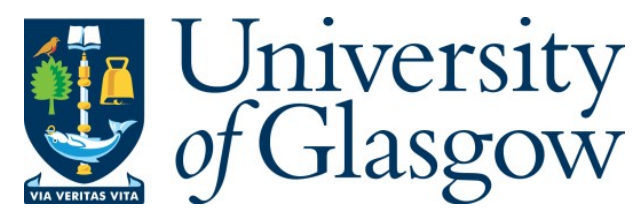

Leith, C., and Wren-Lewis, S. (2011) Discretionary policy in a monetary union with sovereign debt. European Economic Review, 55 (1). pp. 93-117. ISSN 00142921

Copyright (C) 2011 Elsevier

A copy can be downloaded for personal non-commercial research or study, without prior permission or charge

Content must not be changed in any way or reproduced in any format or medium without the formal permission of the copyright holder(s)

When referring to this work, full bibliographic details must be given

http://eprints.gla.ac.uk/46246

Deposited on: 20 November 2013

Enlighten - Research publications by members of the University of Glasgow http://eprints.gla.ac.uk 


\title{
Discretionary Policy in a Monetary Union with Sovereign Debt
}

\author{
Campbell Leith Simon Wren-Lewis \\ University of Glasgow University of Oxford
}

August 30, 2010 


\begin{abstract}
This paper examines the interactions between multiple national fiscal policymakers and a single monetary policy maker in response to shocks to government debt in some or all of the countries of a monetary union. We assume that national governments respond to excess debt in an optimal manner, but that they do not have access to a commitment technology. This implies that national fiscal policy gradually reduces debt: the lack of a commitment technology precludes a random walk in steady state debt, but the need to maintain national competitiveness avoids excessively rapid debt reduction. If the central bank can commit, it adjusts its policies only slightly in response to higher debt, allowing national fiscal policy to undertake most of the adjustment. However if it cannot commit, then optimal monetary policy involves using interest rates to rapidly reduce debt, with significant welfare costs. We show that in these circumstances the central bank would do better to ignore national fiscal policies in formulating its policy.

Acknowledgement 1 This paper was prepared for presentation at the EER Symposium, Philadelphia June 2010. We are grateful for financial support from the ESRC, Grant No. RES-062-23-1436, but the views expressed here are entirely our own. We are also grateful for helpful comments from Eric Leeper, Jim Nason, Paolo Pesenti, Chris Sims, Leopold von-Thadden and participants at the Symposium. Address for correspondence: Campbell Leith, Department of Economics, University of Glasgow, Adam Smith Building, Glasgow G12 8RT. E-mail campbell.leith@glasgow.ac.uk.
\end{abstract}




\section{Overview}

What is the optimal response of the European Central Bank's (ECB) monetary policy to a positive shock to government debt in its member countries? This will depend on how national fiscal policy responds to its own excess debt, which we show is likely to be quite different to how it would respond outside of a monetary union. We analyse a multi-country monetary union where national fiscal authorities operate in the national interest and do not have access to a commitment technology. This alters the analysis of optimal monetary and time-consistent fiscal policy in closed economies in various respects. First, an effective means of influencing debt levels in the closed economy (or in the open economy under flexible exchange rates) is to introduce inflation surprises under flexible prices, or to reduce real debt service costs under sticky prices. Within a monetary union national policy makers no longer have access to monetary policy to achieve this, and any inflation consequences of changes in distortionary taxes will have repercussions on competitiveness with respect to the rest of the monetary union and will ultimately have to be undone. Thus the extent of the time-inconsistency problem can be quite different in the monetary union, relative to the closed economy. Secondly, while the national fiscal authorities are assumed to be too small to interact strategically with each other or the European Central Bank (ECB), the ECB could reasonably be thought to be aware of how national fiscal authorities might react to union-wide economic conditions and may or may not choose to factor this into their optimal policies. We therefore explore how time-consistent national fiscal policies influence ECB behaviour, after allowing for varying degrees of ECB conservatism, ECB mandates and whether or not the ECB can commit. We show that even when national fiscal policies are sound and collectively stabilise union-wide debt stocks, the ECB faces a significant temptation to adjust monetary policy to facilitate national fiscal adjustment and this time-inconsistency problem can be particularly costly in welfare terms.

In terms of modelling, we follow Gali and Monacelli (2008) in considering the case of monetary union consisting of a continuum of small economies, although we extend GM's analysis to include a labour income tax, in addition to government spending, as a national fiscal instrument. More significantly, we also focus on the need to satisfy national government budget constraints through adjustments in distortionary taxes and/or government spending conditional on the monetary policies pursued by the ECB. ${ }^{1}$ We assume that national fiscal authorities seek to maximise national welfare, taking the ECB's monetary policy and the state of the rest of the union as given. Additionally, we assume that the national fiscal authorities do not have access to a commitment technology such that their national fiscal policies are constrained to be time-consistent. The resultant optimal national policies successfully stabilise national government debt gradually through a combination of government spending cuts and tax rises, which are carefully balanced to mitigate the costs of lost competitiveness rel-

\footnotetext{
${ }^{1} \mathrm{GM}$ assume that national governments have access to a lump-sum tax at all points in time such that government debt does not play any part in their analysis.
} 
ative to the rest of the monetary union during the period of fiscal correction. The fact that national fiscal authorities care about competitiveness vis a vis the rest of the monetary union, also implies that increasing price flexibility significantly slows the speed of debt correction - this is in contrast to the case of the closed economy or open economy operating under flexible exchange rates where increasing price flexibility allows inflation surprises to be used to stabilise debt more rapidly.

We then turn to consider the optimal policies of the ECB, where the ECB cares about an aggregate of utility functions across the monetary union, in the light of the aggregate impact of the national fiscal policies. Since the national fiscal authorities are solely concerned with national welfare and take conditions in the rest of the union as given, there is scope for the ECB to act as a Stackelberg leader and take account of the collective national fiscal response to its policies. If the ECB can commit then it moderates its monetary policies slightly to reduce union-wide debt levels, but the bulk of the adjustment takes place through national fiscal adjustment. However, such a policy is inherently time-inconsistent: the ECB is resisting the temptation to introduce a policy surprise to reduce union-wide debt levels and partially avoid the costly national fiscal adjustments that would otherwise take place. When the ECB is assumed not to have access to a commitment technology, then its policy response to a union-wide debt shock is quite different. Although the national fiscal authorities follow policies which stabilise national (and therefore, collectively, union-wide) government debt stocks, the ECB runs a time-consistent policy which aggressively returns union-wide debt to its steady-state value by reducing debt service costs, boosting the union-wide tax base and encouraging national fiscal authorities to cut government spending.

As an alternative description of ECB policy, we assume that the ECB seeks to maximise union-wide welfare but does not recognise national fiscal policies and the national budget constraints as constraints on its policy problem. In other words we allow the ECB to simply ignore the fiscal repercussions of its actions, and therefore its ability to both influence government debt and also the attendant national fiscal responses. Since the national fiscal policies are essentially sound, this is consistent with fiscal stability. If the ECB cannot commit, and is constrained to follow time-consistent policies, then ignoring the fiscal consequences of its actions enables to the ECB to pursue far more reasonable policies with a significant welfare gain.

The results in this paper extend and differ from many earlier results obtained in the context of closed economies. Generally, when fiscal policy does not have access to a commitment technology and is therefore constrained to follow timeconsistent policies, this means that steady state debt no longer follows a random walk (as shown in Leith and Wren-Lewis (2007) in contrast to the random walk results of Schmitt-Grohe and Uribe (2004) and Benigno and Woodford (2003)). In extending this to the case of a monetary union, we show that national debt correction is relatively gradual because of the need to preserve national price competitiveness. This is in sharp contrast to the closed economy 
(or isomorphic flexible exchange rate small open economy ${ }^{2}$ ) case under (timeconsistent) discretion, where optimal debt correction is very rapid (Leith and Wren-Lewis (2007)). As the need to preserve national competitiveness moves the path of debt closer to the commitment solution, it improves welfare under discretion.

The literature that has explored the time-inconsistency of optimal fiscal policy, where policymakers do not have access to non-distortionary tax instruments, has typically assumed a flex price environment. For example, in Lucas and Stokey (1983) surprise inflation effectively acts as a lump-sum tax on real money balances allowing the fiscal consequences of shocks to be dealt with costlessly. In contrast, when monetary injections cannot be fully spent in the period in which they occur (Nicolini, 1998), time consistent policy may actually result in surprise deflations rather than inflations. This and other papers show that the desired long-run level of debt under the time-consistent policy may actually be positive or negative, depending on preferences and whether or not debt is real or nominal (see for example, Diaz-Gimenez et al (2008) and Ellison and Rankin (2007)) or if the government can only issue risk-free debt (Aiuagari et al, 2002). In the case of nominal debt it is the temptation to use surprise inflation/deflation to influence the real level of government debt that drives the time inconsistency problem.

The results in Schmitt-Grohe and Uribe (2004) suggest that even a "miniscule" degree of price stickiness means that it ceases to be optimal (under a Ramsey policy) to use surprise inflation in this way. As a result, it may be thought that the time-inconsistency problem in a sticky-price environment may be slight. Leith and Wren-Lewis (2007) show that this is not the case. They demonstrate that in a closed New Keynesian economy time consistent policy will very rapidly return debt to its (efficient) pre-shock level. While surprise inflation plays some role in this adjustment, most of the correction takes place through a reduction in real debt service costs and an expansion of the tax base in a sticky-price economy. They also show that the inability to commit has a significant welfare cost. In our extension to a monetary union, we show that the time-inconsistency problem facing national fiscal policy makers is less important than that facing the ECB.

In performing the analysis we employ a linear-quadratic approximation to the national and union-wide policy problem for reasons of tractability. In simpler closed economy models (typically with flexible prices) projection techniques (see Herr and Maussner 2009, chapter 6, for a discussion) are often employed to analyse the non-linear policy problem. However, in our multi-country monetary union model both deriving the model, the policy makers' objective functions and aggregating non-linear national fiscal policies without the tractability benefits of a linear-quadratic approximation would be infeasible. ${ }^{3}$

\footnotetext{
${ }^{2}$ Gali and Monacelli (2005) show that the policy problem for the small open economy can be isomorphic to that in the closed economy. While Kirsanova et al. (2008) discuss the conditions under which this holds true.

${ }^{3}$ However, exploring the use of non-linear solution techniques for a monetary union made up of a finite number of economies is an interesting area for future research.
} 
The next section derives the model. Section 3 outlines the social planner's problem such that we can write our model in 'gap' form. This representation of the model can also be used to derive a quadratic approximation to welfare. In section 4 we derive the optimal policies for a continuum of economies participating in monetary union, as well as the ECB's response to those policies. A conclusion summarises the main results.

\section{The Model}

This section outlines our model. As noted above this is similar in structure to GM, but we allow for a distortionary labour income tax and government debt.

\subsection{Households}

There are a continuum of households of size one, and we shall assume full asset markets, such that, through risk sharing, they will face the same budget constraint and make the same consumption plans. As a result the typical household will seek to maximise the following objective function, where for tractability we assume (following GM) that the utility function takes the specific form

$$
E_{0} \sum_{t=0}^{\infty} \beta^{t}\left(\ln C_{t}+\chi \ln G_{t}-\frac{\left(N_{t}\right)^{1+\varphi}}{1+\varphi}\right)
$$

where $\mathrm{C}, \mathrm{G}$ and $\mathrm{N}$ are a consumption aggregate, a public goods aggregate, and labour supply respectively.

The consumption aggregate is defined as

$$
C=\frac{C_{H}^{1-\alpha} C_{F}^{\alpha}}{(1-\alpha)^{(1-\alpha)} \alpha^{\alpha}}
$$

where, if we drop the time subscript, all variables are commensurate. $C_{H}$ is a composite of domestically produced goods given by

$$
C_{H}=\left(\int_{0}^{1} C_{H}(j)^{\frac{\varepsilon-1}{\epsilon}} d j\right)^{\frac{\epsilon}{\epsilon-1}}
$$

where $\mathrm{j}$ denotes the good's type or variety. The aggregate $C_{F}$ is an aggregate across countries $i$

$$
C_{F}=\left(\int_{0}^{1} C_{i}^{\frac{\eta-1}{\eta}} d i\right)^{\frac{\eta}{\eta-1}}
$$

where $C_{i}$ is an aggregate similar to (3). Finally the public goods aggregate is given by

$$
G=\left(\int_{0}^{1} G(j)^{\frac{\varepsilon-1}{\epsilon}} d j\right)^{\frac{\epsilon}{\epsilon-1}}
$$

which implies that public goods are all domestically produced. The elasticity of substitution between varieties $\epsilon>1$ is common across countries. The parameter 
$\alpha$ is (inversely) related to the degree of home bias in preferences, and is a natural measure of openness. This gives rise to the intratemporal allocation of consumption across the various consumption baskets detailed in Appendix 1.

The budget constraint at time $t$ is given by

$$
\begin{aligned}
& \int_{0}^{1} P_{H, t}(j) C_{H, t}(j) d j+\int_{0}^{1} \int_{0}^{1} P_{i, t}(j) C_{i, t}(j) d j d i+Q_{t, t+1} D_{t+1} \\
= & \Pi_{t}+D_{t}+W_{t} N_{t}\left(1-\tau_{t}\right)-T_{t}
\end{aligned}
$$

where $P_{i, t}(j)$ is the price of variety $j$ imported from country $i$ expressed in home currency, $D_{t+1}$ is the nominal payoff of the portfolio held at the end of period $t, \Pi$ is the representative household's share of profits in the imperfectly competitive firms, $W$ are wages, $\tau$ is an wage income tax rate, and $T$ are lump sum taxes. $Q_{t, t+1}$ is the stochastic discount factor for one period ahead payoffs. Using the price indices defined in Appendix 2 this can be rewritten as

$$
P_{t} C_{t}+Q_{t, t+1} D_{t+1}=\Pi_{t}+D_{t}+W_{t} N_{t}\left(1-\tau_{t}\right)-T_{t}
$$

where $P_{t}$ is the consumer price level. Appendix 1 also defines the various price and exchange rate identities.

\subsubsection{Households' Problem}

The first of the household's intertemporal problems involves allocating consumption expenditure across time. We assume that the elasticity of substitution between the baskets of foreign goods produced in different countries is $\eta=1$ (this is equivalent to adopting logarithmic utility in the aggregation of such baskets). We can then maximise utility subject to the budget constraint (7) to obtain the optimal allocation of consumption across time,

$$
\beta\left(\frac{C_{t}}{C_{t+1}}\right)\left(\frac{P_{t}}{P_{t+1}}\right)=Q_{t, t+1}
$$

Taking conditional expectations on both sides and rearranging gives

$$
\beta R_{t} E_{t}\left\{\left(\frac{C_{t}}{C_{t+1}}\right)\left(\frac{P_{t}}{P_{t+1}}\right)\right\}=1
$$

where $R_{t}=\frac{1}{E_{t}\left\{Q_{t, t+1}\right\}}$ is the gross return on a riskless one period bond paying off a unit of domestic currency in $t+1$. This is the familiar consumption Euler equation which implies that consumers are attempting to smooth consumption over time such that the marginal utility of consumption is equal across periods (after allowing for tilting due to interest rates differing from the households' rate of time preference).

A log-linearised version of (9) can be written as

$$
c_{t}=E_{t}\left\{c_{t+1}\right\}-\left(r_{t}-E_{t}\left\{\pi_{t+1}\right\}-\rho\right)
$$


where lowercase denotes logs (with an important exception for $g$ noted below), $\rho=\frac{1}{\beta}-1$, and $\pi_{t}=p_{t}-p_{t-1}$ is consumer price inflation.

The labour supply decision is given by,

$$
(1-\tau)\left(\frac{W}{P}\right)=N^{\varphi} C
$$

where we can see that the distortionary labour income tax will impact on the households' labour supply decisions.

\subsection{International Risk Sharing (IRS)}

We assume symmetric initial conditions (e.g. zero net foreign assets etc) and recalling the first-order condition for consumption, (9), we note that since financial markets are complete, a similar condition must exist in the foreign economy, say country $i$,

$$
\beta\left(\frac{C_{t+1}^{i}}{C_{t}^{i}}\right)^{-1}\left(\frac{P_{t}^{i}}{P_{t+1}^{i}}\right)\left(\frac{\varepsilon_{i, t}}{\varepsilon_{i, t+1}}\right)=Q_{t, t+1}
$$

Equating the two, using the definition of the real exchange rate, $\mathcal{Q}_{i, t}=\frac{\varepsilon_{i t} P_{t}^{*}}{P_{t}}$, and iterating backwards this can be written as,

$$
C_{t}=z^{i} C_{t}^{i} \mathcal{Q}_{i, t}
$$

where $z^{i}$ is a constant which depends upon initial conditions. Log-linearising, integrating over all countries and using the relationship between the terms of trade and the real exchange rate yields,

$$
c=c^{*}+(1-\alpha) s
$$

where $c^{*}=\int_{0}^{1} c^{i} d i$.

\subsection{The Government}

\subsubsection{Allocation of Government Spending}

The allocation of government spending across goods is determined by minimising total costs, $\int_{0}^{1} P_{H}(j) G(j) d j$. Given the form of the basket of public goods this implies,

$$
G(j)=\left(\frac{P_{H}(j)}{P_{H}}\right)^{-\epsilon} G
$$

\subsubsection{Government Debt}

Appendix 3 derives the intertemporal budget constraint for the union as a whole,

$$
\int \varepsilon_{i} D_{t}^{i} d i=-\sum_{T=t}^{\infty} E_{t}\left[Q_{t, T}\left(\int_{0}^{1}\left(P_{i, T} G_{T}^{i}-W_{T}^{i} N_{T}^{i}\left(\tau_{T}^{i}-\varkappa_{i}\right)-T_{T}^{i}\right) d i\right)\right]
$$


where $\int \varepsilon_{i} D_{t}^{i} d i$ is the aggregate level of the national debt stocks and $\varkappa_{i}$ is a steady-state production subsidy which will be used to render the steady-state efficient (see below). With global market clearing in asset markets the series of national budget constraints imply that the only public-sector intertemporal budget constraint in our model is a global constraint. What is the intuition for this? Given complete capital markets and our assumed initial conditions (zero net foreign assets and identical ex ante structures in each economy) this means that initially consumers expect similar fiscal policy regimes in their respective economies. To the extent that ex post this is not the case, there will be state contingent payments under IRS that ensure marginal utilities are equated throughout the world (after controlling for real exchange rate differences). This would seem to suggest that fiscal sustainability questions within this framework are a global rather than a national concern. Further, given that a national government's contribution to global finances is negligible then this could be taken to imply that debt is not an issue in utilising fiscal instruments at the national level.

However, given the fiscal institutions which have been constructed as part of EMU, it seems unlikely that without such constraints each member state would expect to operate under ex ante similar fiscal regimes. Similarly, it seems reasonable to assume that risk sharing of the form adopted in this paper could only exist if there was some homogeneity in fiscal regimes across economies. Therefore we follow Canzoneri et al. (2001) and assume that each government operates with a positive stock of debt such that each economy faces a budget constraint of this form at the national level. Therefore we impose, as an external constraint created within the institutions of EMU or International Risk Sharing, a national government budget constraint of the form,

$$
D_{t}^{i}=-\sum_{T=t}^{\infty} E_{t}\left[Q_{t, T}\left(P_{i, T} G_{T}^{i}-W_{T}^{i} N_{T}^{i}\left(\tau_{T}^{i}-\varkappa_{i}\right)-T_{T}^{i}\right)\right]
$$

In order to support the assumption that the steady-state level of output is efficient (which facilitates the derivation of welfare functions below) an obvious assumption to make is that lump-sum taxation is used to finance the steady-state subsidy (which offsets, in steady-state, the distortions caused by distortionary taxation and imperfect competition in price setting). We shall then assume that lump-sum taxation cannot be used to alter this subsidy or to finance any other government activities, including the kind of spending and distortionary tax adjustments as stabilisation measures we are interested in. This implies that $W_{T}^{i} N_{T}^{i} \varkappa_{i}=T_{T}^{i}$ in all our economies at all points in time, allowing us to simplify the budget constraint to,

$$
B_{t-1}^{i} R_{t-1}=-\sum_{T=t}^{\infty} E_{t}\left[Q_{t, T}\left(P_{i, T} G_{T}^{i}-W_{T}^{i} N_{T}^{i} \tau_{T}^{i}\right)\right]
$$

i.e. distortionary taxation and spending adjustments are required to service government debt as well as stabilise the economy. This defines the basic tradeoff facing policy makers in utilising these instruments. 
This intertemporal budget constraint implies the flow budget constraint for the national government, in real terms,

$$
\frac{b_{t}^{i}}{R_{t}}=\frac{P_{i, t-1}}{P_{i, t}} b_{t-1}^{i}+G_{t}^{i}-\frac{W_{t}^{i}}{P_{i, t}} N_{t}^{i} \tau_{t}^{i}
$$

where $b_{t}^{i}=\frac{B_{t}^{i} R_{t}}{P_{i, t}}$. Since we are considering cashless economies there are no seigniorage revenue transfers resulting from the ECB's monetary policies.

\subsection{Firms}

The production function is linear, so for firm $j$

$$
Y(j)=A N(j)
$$

where $a=\ln (A)$ is time varying and stochastic. The demand curve they face is given by,

$$
Y(j)=\left(\frac{P_{H}(j)}{P_{H}}\right)^{-\epsilon}\left[(1-\alpha)\left(\frac{P C}{P_{H}}\right)+\alpha \int_{0}^{1}\left(\frac{\varepsilon_{i} P^{i} C^{i}}{P_{H}}\right) d i+G\right]
$$

which we rewrite as,

$$
Y(j)=\left(\frac{P_{H}(j)}{P_{H}}\right)^{-\epsilon} Y
$$

where $Y=\left[\int_{0}^{1} Y(j)^{\frac{\epsilon-1}{\epsilon}} d j\right]^{\frac{\epsilon}{\epsilon-1}}$. The objective function of the firm is given by,

$$
\sum_{s=0}^{\infty}(\theta)^{s} Q_{t, t+s}\left[\frac{P_{H}(j)_{t}}{P_{t+s}} Y(j)_{t+s}-\frac{W_{t+s}}{P_{t+s}} \frac{Y(j)_{t+s}(1-\varkappa)}{A_{t+s}}\right]
$$

where $\varkappa$ is an employment subsidy which can be used to eliminate the steadystate distortion associated with monopolistic competition and distortionary labour income taxes (assuming there is a lump-sum tax available to finance such a subsidy). Solving for the optimal reset price, which is common across all firms able to reset prices in period $t$,

$$
\bar{P}_{H, t}=\frac{\sum_{s=0}^{\infty}(\theta)^{s} Q_{t, t+s}\left[\epsilon \frac{W_{t+s}}{P_{t+s}} P_{H, t+s}^{\epsilon} \frac{Y_{t+s}}{A_{t+s}}\right]}{\sum_{s=0}^{\infty}(\theta)^{s} Q_{t, t+s}\left[(\epsilon-1) P_{t+s}^{-1} P_{H, t+s}^{\epsilon} Y_{t+s}(1-\varkappa)\right]}
$$

Domestic prices evolve according to,

$$
P_{H, t}=\left[\left(1-\theta_{w}\right) \bar{P}_{H, t}^{(1-\epsilon)}+\theta_{w} P_{H, t-1}^{1-\epsilon}\right]^{\frac{1}{1-\epsilon}}
$$

Appendix 4 then details the derivation of the New Keynesian Phillips curve for domestic price inflation which is given by,

$$
\pi_{H, t}=\beta E_{t} \pi_{H, t+1}+\lambda\left(m c_{t}+\ln \left(\mu_{t}\right)\right)
$$


where $\lambda=\frac{(1-\theta \beta)(1-\theta)}{\theta}$ and $m c=-a+w-p_{H}-v=-a+p-p_{H}+\varphi n+$ $c-\ln (1-\tau)-v$ are the real log-linearised marginal costs of production, and $v=-\ln (1-\varkappa)$. In the absence of sticky prices profit maximising behaviour implies, $m c_{t}=-\ln \left(\mu_{t}\right)$ where $\mu_{t}$ is the desired mark-up.

\subsection{Equilibrium}

Using the definition of aggregate output and the firm's demand curve (21) allows us to write

$$
\begin{aligned}
Y & =(1-\alpha) \frac{P C}{P_{H}}+\alpha \int_{0}^{1}\left(\frac{\varepsilon_{i} P^{i} C^{i}}{P_{H}}\right) d i+G \\
& =S^{\alpha}\left[(1-\alpha) C+\alpha \int_{0}^{1} \mathcal{Q}_{i} C_{i} d i\right]+G \\
& =C S^{\alpha}+G
\end{aligned}
$$

Taking logs implies

$$
\begin{aligned}
y-g & =c+\alpha s \\
& =c^{*}+s
\end{aligned}
$$

where we define $g=-\ln \left(1-\frac{G}{Y}\right)$. As this condition holds for all countries, and $\int_{0}^{1} s^{i} d i=0$, we have

$$
y^{*}=\int_{0}^{1}\left(c^{i}+g^{i}\right) d i=c^{*}+g^{*}
$$

From the definition of the terms of trade, within a monetary union this implies the following link between competitiveness and national output,

$$
\Delta y_{t}=\Delta g_{t}+\Delta c_{t}^{*}+\pi_{t}^{*}-\pi_{H, t}
$$

which forms an additional constraint on the national policymaker.

\subsection{Summary of Model}

We are now in a position to summarise our model. For a representative union member, $i$, on the demand side we have an Euler equation for consumption,

$$
y_{t}^{i}=E_{t}\left\{y_{t+1}^{i}\right\}-\left(r_{t}-E_{t}\left\{\pi_{i, t+1}\right\}-\rho\right)-E_{t}\left\{g_{t+1}^{i}-g_{t}^{i}\right\}
$$

but where the nominal interest rate, $r_{t}$, is under the control of the ECB and not a national monetary authority. On the supply side there is an equation for domestic price inflation,

$$
\pi_{i, t}=\beta E_{t}\left\{\pi_{i, t+1}\right\}+\lambda\left(m c_{t}^{i}+\ln \left(\mu_{t}^{i}\right)\right)
$$


where $\lambda=[(1-\beta \theta)(1-\theta)] / \theta$ and $m c_{t}^{i}=-a_{t}^{i}+w_{t}^{i}-p_{i, t}-\ln \left(1-\tau_{t}^{i}\right)-v=$ $(1+\varphi)\left(y_{t}^{i}-a_{t}^{i}\right)-\ln \left(1-\tau_{t}^{i}\right)-g_{t}^{i}$ and there is the government budget constraint,

$$
\begin{aligned}
\beta\left(\widehat{b}_{t}^{i}-r_{t}\right)= & \left(\widehat{b}_{t-1}^{i}-\pi_{i, t}\right)+\frac{\bar{G}^{i}}{\bar{B}^{i}}\left(\frac{1-\gamma^{i}}{\gamma^{i}} \widehat{g}_{t}^{i}+\widehat{y}_{t}^{i}\right) \\
& -\frac{\bar{\tau} \bar{W}^{i} \bar{N}^{i}}{\bar{B}^{i}}\left((1+\varphi)\left(\widehat{y}_{t}^{i}-a_{t}^{i}\right)+\widehat{y}_{t}^{i}-\widehat{g}_{t}^{i}+\frac{1}{1-\tau} \tau_{t}^{i}\right)
\end{aligned}
$$

If this was a small open economy operating its own monetary policy then this would be sufficient to describe the domestic economy. However, as a result of joining the monetary union, an individual economy has lost control of the monetary policy instrument and they must take account of the repercussions of their actions on competitiveness,

$$
\Delta y_{t}^{i}=\Delta g_{t}^{i}+\Delta c_{t}^{*}+\pi_{t}^{*}-\pi_{H, t}^{i}
$$

For the union as a whole,

$$
y_{t}^{*}=g_{t}^{*}+c_{t}^{*}
$$

where $y_{t}^{*}=\int_{0}^{1} y_{t}^{i} d i, c_{t}^{*}=\int_{0}^{1} c_{t}^{i} d i, g_{t}^{*}=\int_{0}^{1} g_{t}^{i} d i, b_{t}^{*}=\int_{0}^{1} b_{t}^{i} d i$ and $\pi_{t}^{*}=\int_{0}^{1} \pi_{t}^{i} d i$

The model is then closed by policy makers specifying the appropriate values of the fiscal and monetary policy variables. However, although this represents a fully specified model it is often recast in the form of 'gap' variables which are more consistent with utility-based measures of welfare. This transformation is contained in Appendix 5.

\section{Optimal policy}

\subsection{The Social Planner's Problem in a Monetary Union}

In order to develop an objective function with which to evaluate optimal policy it is helpful to begin by analysing the social planner's problem. The social planner simply decides how to allocate consumption and production of goods within the economy, subject to the various constraints implied by operating as part of a larger group of economies e.g. International Risk Sharing (IRS). Since he is concerned with real allocations, the social planner ignores nominal inertia and distortionary taxation in describing optimal allocations. Accordingly, the solution to the social planner's problem provides a benchmark for optimal policy, and can be used to compute the steady-state subsidy which would ensure the steady-state is efficient. In the face of shocks it is often optimal to deviate from this steady-state and stabilisation policy can then be based on attempting to ensure such deviations are as close to optimal as is possible given the various 
sources of nominal inertia and distortionary taxation which are present in the model.

Here the social planner maximises utility across all countries subject to

$$
\begin{aligned}
Y^{i} & =A^{i} N^{i} \\
Y^{i} & =C_{i}^{i}+\int_{0}^{1} C_{i}^{j} d j+G^{i}
\end{aligned}
$$

Recall that utility for country $i$ at time $t$ is

$$
\ln C_{t}^{i}+\chi \ln G_{t}^{i}-\frac{\left(N_{t}^{i}\right)^{1+\varphi}}{1+\varphi}
$$

and

$$
C^{i}=\left(Y^{i}-G^{i}\right)^{1-\alpha}\left[\int_{0}^{1} C_{i}^{j} d j\right]^{\alpha}
$$

Optimisation implies

$$
\left(N^{i}\right)^{\varphi}=A^{i} \frac{1-\alpha}{C_{i}^{i}}=A^{i} \int_{0}^{1} \frac{\alpha}{C_{i}^{j}} d j=A^{i} \frac{\chi^{i}}{G^{i}}
$$

and,

$$
\begin{aligned}
N^{i} & =\left(1+\chi^{i}\right)^{\frac{1}{1+\varphi}} \\
C^{i} & =\left(\frac{1-\alpha}{1+\chi^{i}}\right) Y^{i} \\
C_{i}^{j} & =\left(\frac{\alpha}{1+\chi^{i}}\right) Y^{i} \quad j \neq i \\
G^{i} & =\frac{\chi^{i}}{1+\chi^{i}} Y^{i}=\frac{\chi^{i} A^{i}}{\left(1+\chi^{i}\right)^{\frac{\varphi}{1+\varphi}}}
\end{aligned}
$$

The latter implies $g=\ln \left(1+\chi^{i}\right)$ which is a different fiscal rule than in the case of the small open economy. Why? In the small open economy case governments have an incentive to increase government spending (which is devoted solely to domestically produced goods) to induce an appreciation in the terms of trade. In aggregate this cannot happen, but it leaves government spending inefficiently high. The government spending rule under monetary union eliminates this externality. This also has implications for the derivation of union and national welfare which are discussed below.

\subsection{Social Welfare}


Appendix 6 derives the quadratic approximation to utility across member states to obtain a union-wide objective function.

$$
\begin{aligned}
\Gamma= & -\frac{(1+\chi)}{2} \sum_{t=0}^{\infty} \beta^{t} \int_{0}^{1}\left[\frac{\epsilon}{\lambda} \pi_{i, t}^{2}+\left(y_{t}^{i, g}\right)^{2}(1+\varphi)+\frac{1}{\chi}\left(g_{t}^{i, g}\right)^{2}\right] d i \\
& +t i p+o\left(\|a\|^{3}\right)
\end{aligned}
$$

It contains quadratic terms in price inflation reflecting the costs of price dispersion induced by inflation in the presence of nominal inertia, as well as terms in the output gap and government spending gap. The weights attached to each element are a function of deep model parameters. The key to obtaining this quadratic specification is in adopting an employment subsidy which eliminates the distortions caused by imperfect competition in product markets as well as the impact of distortionary income taxes. It is also important to note that it is assumed that national fiscal authorities have internalised the externality caused by their desire to appreciate the terms of trade relative to other union-members through excessive government expenditure.

In performing the analysis we employ a linear-quadratic approximation to the national and union-wide policy problem for reasons of tractability. In simpler closed economy models (typically with flexible prices) projection techniques (see Herr and Maussner 2009, chapter 6, for a discussion) are often employed to analyse the non-linear policy problem. However, in our multi-country monetary union model both deriving the model, the policy makers' objective functions and aggregating non-linear national fiscal policies without the tractability benefits of a linear-quadratic approximation would be infeasible. An alternative approach to developing a valid linear-quadratic approximation to the policy problem is outlined in Benigno and Woodford (2003), who show that taking second order approximations of some key model equations can allow one to eliminate the linear terms that would otherwise be present when the steady-state is inefficient. This approach has been applied to the two-country monetary-union case by Ferrero (2006), but this approach can only consider optimal policy from the timeless perspective, whereas we wish to focus on discretionary policy.

Appendix 6 also derives the objective function for the individual union member as,

$$
\begin{aligned}
\Psi^{i}= & -\frac{(1+\chi)}{2} \sum_{t=0}^{\infty} \beta^{t}\left[\frac{\epsilon}{\lambda} \pi_{i, t}^{2}+(1+\varphi)\left(y_{t}^{i, g}+\frac{\alpha}{(1+\chi)(1+\varphi)}\right)^{2}\right. \\
& \left.+\frac{1}{\chi}\left(g_{t}^{i, g}-\frac{\alpha \chi}{(1+\varphi)(1+\chi)}\right)^{2}\right]+t i p+o\left(\|a\|^{3}\right)
\end{aligned}
$$

This contains linear terms which capture the desire of national fiscal authorities to manipulate their terms-of-trade to their national advantage. These terms are not present in the union-wide welfare function as collectively it is futile for all union members to attempt to change their terms of trade. However, in order to avoid introducing a permanent conflict between national and unionwide objectives we assume that individual union members resist the (collectively 
pointless) temptation to exploit their neighbours in this way and we set these linear terms to zero. However, there is no coordination beyond this, and in response to shocks the national fiscal authorities will only consider national welfare in setting policy and will take union-wide economic conditions as given, thereby ignoring their aggregate impact on the union-wide economy..

Note we can decompose union wide welfare as the sum of quadratic terms in union-wide aggregates and the cross-sectional variance across the union,

$$
\begin{aligned}
\Gamma= & -\frac{(1+\chi)}{2} \sum_{t=0}^{\infty} \beta^{t} \int_{0}^{1}\left[\frac{\epsilon}{\lambda}\left(\pi_{i, t}-\pi_{t}^{*}\right)^{2}+\left(y_{t}^{i, g}-y_{t}^{*, g}\right)^{2}(1+\varphi)+\frac{1}{\chi}\left(g_{t}^{i, g}-g_{t}^{*, g}\right)^{2}\right] d i \\
& -\frac{(1+\chi)}{2} \sum_{t=0}^{\infty} \beta^{t}\left[\frac{\epsilon}{\lambda}\left(\pi_{t}^{*}\right)^{2}+\left(y_{t}^{*, g}\right)^{2}(1+\varphi)+\frac{1}{\chi}\left(g_{t}^{*, g}\right)^{2}\right] \\
& +t i p+o\left(\|a\|^{3}\right)
\end{aligned}
$$

Since all economies are loglinearised around the same steady-state the ECB can only affect the mean across the union and not the variance across union members, it is only the second line of this welfare measure that is relevant for the ECB in setting union-wide monetary policy.

\section{Responding to Debt Shocks}

In this section we examine the optimal policy response to both idiosyncratic (national) and union-wide debt shocks. We consider discretionary and commitment policies and compute the welfare benefits of employing our various fiscal and monetary instruments as stabilisation devices. Following GM we adopt the following parameter set, $\varphi=1, \mu=1.2, \epsilon=6, \theta=0.7, \beta=0.99, \alpha=0.4$, and $\gamma=0.25$. The ratio of government spending to gdp of 0.25 implies that $\chi=\frac{\gamma}{1-\gamma}=1 / 3$ in the MU case. The ratio of consumption to steady-state output will therefore be 0.75 , with $60 \%$ of that devoted to domestically produced goods. In contrasting the policy responses to debt shocks we shall focus on helicopter drops of government bonds. However, in computing welfare we shall allow debt to be buffeted by a mixture of technology and mark-up shocks. The productivity shock follows the following pattern,

$$
a_{t}=\rho_{a} a_{t-1}+\xi_{t}
$$

where, following the Bayesian estimation of Smets and Wouters (2005) for the Euro area we adopt a degree of persistence in the productivity shock of $\rho_{a}=0.99$ with a standard deviation of 0.69 . While the iid mark-up shock has a standard deviation of 0.19 . 


\subsection{National Fiscal Policies}

The national fiscal authorities face the following policy problem whereby they seek to minimise their contribution to the union-wide welfare,

$$
\begin{aligned}
\Psi^{i}= & -\frac{(1+\chi)}{2} \sum_{t=0}^{\infty} \beta^{t}\left[\frac{\epsilon}{\lambda} \pi_{i, t}^{2}+(1+\varphi)\left(y_{t}^{i, g}\right)^{2}+\frac{1}{\chi}\left(g_{t}^{i, g}\right)^{2}\right] \\
& +t i p+o\left(\|a\|^{3}\right)
\end{aligned}
$$

In constructing this welfare measure we assume that by participating in the monetary union the national fiscal authorities do not attempt to utilise their instruments to achieve a devaluation relative to other union members, which collectively cannot happen. Therefore, the national fiscal authorities internalise this particular externality, but still take the state of the rest of the union as given when conducting national fiscal policy.

The constraints faced by the national fiscal authority are the national NKPC,

$$
\pi_{i, t}=\beta E_{t}\left\{\pi_{i, t+1}\right\}+\lambda\left[(1+\varphi) y_{t}^{i, g}-g_{t}^{i, g}+\frac{\tau}{1-\tau} \tau_{t}^{i, g}\right]
$$

the impact of national policies on competitiveness vis a vis the rest of the union

$$
\Delta y_{t}^{i, g}=\Delta g_{t}^{i, g}+\Delta c_{t}^{*, g}+\pi_{t}^{*}-\pi_{i, t}-\Delta a_{t}^{i}+\Delta a_{t}^{*}
$$

and the national government budget constraint,

$$
\begin{aligned}
\beta \widehat{b}_{t}^{i}= & \left.\beta\left(-c_{t}^{*, g}+E_{t}\left\{c_{t+1}^{*, g}\right\}+E_{t}\left\{\pi_{t+1}^{*}\right\}\right)+\widehat{b}_{t-1}^{i}-\pi_{i, t}\right)+\left(\frac{\bar{G}^{i}}{\bar{B}^{i}} \frac{1-\gamma^{i}}{\gamma^{i}}+\frac{\bar{\tau}^{i} \bar{N}^{i}}{\bar{B}^{i}}\right) g_{t}^{i, g} \\
& -(\bar{R}-1) y_{t}^{i, g}-\frac{\bar{\tau} \bar{W}^{i} \bar{N}^{i}}{\bar{B}^{i}}\left((1+\varphi)\left(y_{t}^{i, g}\right)+\frac{1}{1-\tau} \tau_{t}^{i, g}\right) \\
& -(\bar{R}-1) a_{t}^{i}+\frac{\bar{W}^{i} \bar{N}^{i}}{\bar{B}^{i}} \mu_{t}^{i}+\beta a_{t}^{*}(1-\rho)
\end{aligned}
$$

In solving the model we use the Matlab codes of Soderlind(1999). Soderlind considers a model in the following form,

$$
\left[\begin{array}{c}
\mathbf{x}_{1 t+1} \\
E_{t} \mathbf{x}_{2 t+1}
\end{array}\right]=\mathbf{A}\left[\begin{array}{c}
\mathbf{x}_{1 t} \\
\mathbf{x}_{2 t}
\end{array}\right]+\mathbf{B} \mathbf{u}_{t}+\left[\begin{array}{c}
\boldsymbol{\varepsilon}_{t+1} \\
\mathbf{0}
\end{array}\right]
$$

where $\mathbf{x}_{1 t}$ is a vector of predetermined variables, $x_{2 t}$ are jump variables, $\mathbf{u}_{t}$ are controls and $\varepsilon_{t}$ are shocks to the predetermined variables. The policy maker's objectives are given by,

$$
J_{0}=E_{0} \sum_{t=0}^{\infty} \beta^{t}\left[\mathbf{x}_{t}^{\prime} \mathbf{Q} \mathbf{x}_{t}+2 \mathbf{x}_{t}^{\prime} \mathbf{U} \mathbf{u}_{t}+\mathbf{u}_{t}^{\prime} \mathbf{R} \mathbf{u}_{t}\right]
$$


This can either be solved under discretion or commitment, but we focus on discretion in the context of national fiscal policies since it is far from clear that national governments have access to a commitment technology.

We can construct the policy problem for the national economy, taking unionwide variables as given, as shown in Appendix 7(1). Using the Oudiz and Sachs (1985) iterative procedure this delivers a solution of the form,

$$
\mathbf{x}_{1 t+1}=\mathbf{M x}_{1 t}+\varepsilon_{t+1}, \mathbf{x}_{2 t}=\mathbf{C} \mathbf{x}_{1 t} \text { and } \mathbf{u}_{t}=\mathbf{F} \mathbf{x}_{1 t}
$$

Figure 1 details the national fiscal response to a $1 \%$ shock to national debt. This shock is analogous to a helicopter drop of money, but applied to government bonds. It is a useful device in describing the policy response to fiscal shocks without complicating the analysis by assuming the fiscal shock is driven by a more fundamental shock (such as a technology shock) which would, in itself, result in a desired policy response in addition to the need to satisfy the government's intertemporal budget constraint. When we consider the welfare consequences of alternative policy regimes below, we do not include such shocks, but consider more standard technology shocks which have fiscal consequences.

In response to the higher national debt, the fiscal authorities cut government spending and raises tax rates. Although the lower government spending reduces aggregate demand, the higher distortionary tax rates discourages labour supply and fuels firms' marginal costs. The higher inflation that emerges implies that the domestic economy is losing competitiveness, which further reduces output and consumption. Eventually, this comes to dominate the higher tax rate and inflation turns negative as the economy slowly regains its lost competitiveness. A notable feature of this impulse response is that the correction of debt is gradual.

For the functional forms and parameterisation considered in this study, if our economies were to operate under flexible exchange rates the policy problem is isomorphic to the closed economy cases analysed in Leith and Wren-Lewis (2008) where time consistency implies a very rapid fiscal correction, primarily through reductions in real interest rates in a sticky-price environment. Nevertheless, in order to make clear the difference between the response to the debt shock inside or outside of a monetary union, Figure 2 plots the impulse response of Figure 1 alongside the response to the same shock if the national policies operate under flexible exchange rates and retain use of a national monetary policy instrument. In this case, the national monetary authority would cut interest rates, reducing debt service costs, boosting output and the tax base and fueling inflation. Government spending falls, and tax rates rise (although with more flexible prices tax rates can fall to moderate the increase in inflation that would otherwise emerge).

At first it may appear that the gradual fiscal correction within a monetary union is due to the fact that national policy makers do not have access to a monetary policy instrument to engineer the desired change in real interest rates. However, the distortionary tax rates could achieve significant movements in real interest rates through their impact on domestic inflation such that slower 
fiscal correction is not due to a lack of instruments. Instead, the main driving force behind the slow adjustment is the fact that within a monetary union the fiscal authorities are constrained by the need to restore competitiveness between the national economy and the rest of the monetary union. This inhibits the use of distortionary taxes to manipulate domestic inflation and thereby real debt service costs since any inflation generated subsequently has to be undone to regain competitiveness. This greatly mitigates the time inconsistency problem detailed in Leith and Wren-Lewis (2008).

We can further explore the sensitivity of the speed of national fiscal correction to different debt-gdp ratios and degrees of price stickiness. Figure 3 plots the half-life of debt (the time it takes debt to return half way to its steady-state value) as a function of the steady-state debt to GDP ratio and the degree of price stickiness. While debt levels do not have a significant influence, the speed of debt correction is strongly inversely related to the extent of price stickiness. This strongly contrasts to the closed economy literature where price stickiness reduces the ability of inflation surprises to stabilise debt quickly (or costlessly and instantaneously in the limiting case of flexible prices - see Schmitt-Grohe and Uribe (2004)). The reason is quite intuitive. When prices are relatively flexible, any attempt to move fiscal instruments to stabilise debt will generate more inflation with a greater impact on competitiveness. This inhibits the fiscal authority and results in a slow fiscal response which is close to the random walk found under commitment (see Schmitt-Grohe and Uribe (2004) and Benigno and Woodford (2003)).

Finally, we explore the impact of competitiveness on the speed of fiscal correction. Figure 4 considers the same debt shock as Figure 1, but combined it with a negative competitiveness shock of $1 \%$. With the competitiveness shock the adjustment of debt is relatively more rapid (although still no where near the speed of correction one finds under flexible exchange rates). Moreover, if we contrast the impulse response to the combined competitiveness and debt shock, with the case of only a competitiveness shock without any direct debt shock then the marginal effect of the shock to debt is much the same as the case of a debt shock alone. In other words, the marginal national fiscal response to the fiscal consequences of shocks is not greatly affected by the national economy's initial competitiveness position. These results are summarised in Table 1.

Table 1 - Summary of National Fiscal Policy Experiments

\begin{tabular}{|l|l|l|l|l|l|}
\hline Fig. & Regime & Time Consistent? & $\frac{D e b t}{G D P}$ & Price Stickiness, $\theta$ & Debt Adjustment. \\
\hline 1 & EMU & Yes & $60 \%$ & 0.7 & Gradual \\
\hline 2 & Flex er & Yes & $60 \%$ & 0.7 & Rapid \\
\hline 3 & EMU & Yes & $0-100 \%$ & $0-0.75$ & Gradual \\
\hline 4 & $\Delta$ Competitiveness & Yes & $60 \%$ & 0.7 & Gradual \\
\hline
\end{tabular}

\subsection{ECB's Response to National Fiscal Policies}


We now turn to consider the implications for this national fiscal behaviour for the ECB. Essentially, by implementing a policy like the one just described, the national fiscal authorities will be ensuring fiscal stabilisation whatever the state of the rest of the union. Accordingly, the ECB could choose to ignore the fiscal consequences of their actions without jeopardising national or union-wide fiscal solvency. In maximising social welfare the ECB may take into account the impact that high debt will have on distortionary taxes and therefore output and inflation, and in addition will know that monetary policy can influence the level of debt.

Formally, the ECB's optimisation problem assumes they are seeking to minimise union wide losses,

$$
\begin{aligned}
\Gamma= & \frac{(1+\chi)}{2} \sum_{t=0}^{\infty} \beta^{t}\left[\frac{\epsilon}{\lambda}\left(\pi_{t}^{*}\right)^{2}+\left(y_{t}^{*, g}\right)^{2}(1+\varphi)+\frac{1}{\chi}\left(g_{t}^{*, g}\right)^{2}\right] \\
& +t i p+o\left(\|a\|^{3}\right)
\end{aligned}
$$

where the variance in outcomes across member states is collected in the tip term as the ECB cannot influence the cross-sectional variance of outcomes across the symmetrical economies which have entered the monetary union. The aggregate constraints facing the ECB are given by the NKPC,

$$
\pi_{t}^{*}=\beta E_{t}\left\{\pi_{t+1}^{*}\right\}+\lambda\left[(1+\varphi) y_{t}^{*, g}-g_{t}^{*, g}+\frac{\tau}{1-\tau} \tau_{t}^{*, g}\right]
$$

the union-wide national accounting identity,

$$
y_{t}^{*, g}=g_{t}^{*, g}+c_{t}^{*, g}
$$

and the union-wide government budget constraint,

$$
\begin{aligned}
\widehat{\beta b_{t}^{*}=} & \beta\left(-c_{t}^{*, g}+E_{t}\left\{c_{t+1}^{*, g}\right\}+E_{t}\left\{\pi_{t+1}^{*}\right\}\right)+\left(\widehat{b}_{t-1}^{*}-\pi_{*, t}\right)+\left(\frac{\bar{G}^{*}}{\bar{B}^{*}} \frac{1-\gamma^{*}}{\gamma^{*}}+\frac{\bar{\tau}^{*} \bar{N}^{*}}{\bar{B}^{*}}\right) g_{t}^{*, g} \\
& -(\bar{R}-1) y_{t}^{*, g}-\frac{\bar{\tau} \bar{W}^{*} \bar{N}^{*}}{\bar{B}^{*}}\left((1+\varphi)\left(y_{t}^{*, g}\right)+\frac{1}{1-\tau} \tau_{t}^{*, g}\right) \\
& -(\bar{R}-1) a_{t}^{*}+\frac{\bar{W}^{*} \bar{N}^{*}}{\bar{B}^{*}} \mu_{t}^{*}+\beta a_{t}^{*}(1-\rho)
\end{aligned}
$$

The ECB also considers the aggregate fiscal behaviour of the national fiscal authorities. Under discretion, the national fiscal authorities will implement policy rules which relate their instruments $\left(\mathbf{u}_{t}^{i}\right.$ - government spending and distortionary tax rates) to the state variables (national debt, national technology and mark-up shocks, national competitiveness, and union-wide variables) $\mathbf{u}_{t}^{i}=\mathbf{F x}_{1 t}^{i}$. Since all economies in the monetary union are symmetrical, the form of the national fiscal response is the same for each member state (although different shocks may imply different debt levels and levels of competitiveness across member states at any point in time) which means that the national fiscal reaction functions 
can be aggregated. This allows us to embed the aggregate of the national fiscal responses in the ECB's policy problem as described in Appendix 7(2).

We can then solve the ECB's policy problem under either discretion or commitment where it knows the fiscal reaction function of the national fiscal authorities. Both cases are considered in Figure 4 which details the union-wide response to an aggregate debt shock of $1 \%$. Under commitment, the ECB no longer follows the random walk in steady-state debt we typically observe in the closed or flexible exchange rate open economy cases. The reason is that the ECB takes into account the repercussions of its actions on debt and the national fiscal responses to that. Under commitment, the ECB cuts union-wide interest rates to help reduce union wide debt, but only moderately such that the debt stabilisation remains gradual. In contrast, under discretion, the ECB aggressively moves its interest rate instrument to return union-wide debt levels to steady-state. In fact it is so aggressive that it actually overshoots within a single period. In this case the ECB cannot resist the time-inconsistency problem that the national fiscal authorities partially can by facing a competitiveness constraint, and is compelled to act to stabilise the debt very quickly.

Why? Unless inflationary expectations are particularly high the ECB has an incentive to introduce policy surprises in order to stabilise debt at a lower cost than implied by the collective national fiscal adjustments. Anticipating such behaviour inflationary expectations rise until the ECB no longer has the incentive to introduce policy surprises. However the welfare costs of this are so great that the ECB will seek to eliminate excess debt and the attendant timeconsistency problem as quickly as possible. The overcorrection occurs because even with a complete correction the policy maker would still have incentives to introduce policy surprises to change the policy mix used to stabilise the debt. In a Euro area economy subject to the technology and mark-up shocks estimated by Smets and Wouters (2005), the welfare consequences of this are significant with the costs of union-wide technology and mark-up shocks rising from $0.00001726 \%$ of steady-state consumption to $0.0141 \%$ of steady-state consumption as we move from commitment to discretion. ${ }^{4}$

If we increase the weight attached to inflation by the ECB then the rapid fiscal correction under discretion is unaffected unless the weight is significantly increased, to levels which imply that the ECB is effectively a strict inflation targeter. For example with a probability of no price change of $\theta=0.6$, the weight on inflation has to increase 13 fold to prevent ECB from utilising its instrument to stabilise government debt across the monetary union. In other words, even although the national fiscal authorities are running sound fiscal policies which are capable of stabilising debt in an orderly manner, in the absence

${ }^{4}$ The relatively small value of the welfare number under commitment, reflects the richness of the instrument set available to policy makers, where, if lump sum taxes where available to satisfy the intertemporal budget constraint, the national policy makers would be able to perfectly stabilise their economies in the face of idiosyncratic shocks and the ECB in the face of union-wide shocks. Adding additional frictions such as sticky wages would raise this number, but the relative costs of time-consistency would remain - see Leith and Wren-Lewis (2007). 
of a commitment technology, the ECB cannot resist the temptation to offset the costs of national fiscal corrections by using monetary policy to influence average debt levels in the monetary union.

\subsection{The Conventional Assignment}

While it is conventional in the literature to assume that monetary policy maximises social welfare (under discretion or commitment), the relationship between monetary and fiscal policy in many countries is often characterised as an assignment regime. Monetary policy is assigned short term stabilisation of output and inflation, and fiscal policy is assigned control of government debt (Kirsanova et al. (2009) call this the 'conventional assignment'). Although this assignment is most often discussed in terms of the merits or otherwise of fiscal countercyclical policy (see Eser et al. (2009)), it also implicitly implies that monetary policy should not concern itself with government debt. Of course government debt does not appear directly in any measure of social welfare, but it does impact on that measure indirectly because debt has to be financed and taxes are distortionary. As the previous section showed, this can mean that monetary does react strongly to debt if it maximises social welfare.

Given this, how can we characterise the conventional assignment within an optimisation framework, and potentially avoid monetary policy responding to debt under discretion? In what follows we assume that the ECB still seeks to maximise social welfare, but takes national fiscal variables as given and ignores the existence of national government budget constraints. Consider the ECB's objective function,

$$
\Gamma=-\frac{(1+\chi)}{2} \sum_{t=0}^{\infty} \beta^{t}\left[\frac{\epsilon}{\lambda}\left(\pi_{t}^{*}\right)^{2}+\left(y_{t}^{*, g}\right)^{2}(1+\varphi)\right]+t i p+o\left(\|a\|^{3}\right)
$$

The term in government spending is now taken as given and is considered as tip in the ECB's optimisation. The aggregate constraints facing the ECB are given by the aggregate NKPC,

$$
\pi_{t}^{*}=\beta E_{t}\left\{\pi_{t+1}^{*}\right\}+\lambda\left[(1+\varphi) y_{t}^{*, g}-g_{t}^{*, g}+\frac{\tau}{1-\tau} \tau_{t}^{*,} g^{\prime}\right]
$$

and the national accounting identity for the union as a whole,

$$
y_{t}^{*, g}=g_{t}^{*, g}+c_{t}^{*, g}
$$

Under commitment the first order conditions for the ECB's policy problem are given by,

$$
\frac{\epsilon}{\lambda}\left(\pi_{t}^{*}\right)+\Delta \lambda_{t}^{\pi}=0
$$

and

$$
\left(y_{t}^{*, g}\right)(1+\varphi)-\lambda(1+\varphi) \lambda_{t}^{\pi}=0
$$


where $\lambda_{t}^{\pi}$ is the Lagrange multiplier associated with the union-wide NKPC. When the first order conditions are combined we obtain the target criterion,

$$
\epsilon\left(\pi_{t}^{*}\right)=\Delta\left(y_{t}^{*, g}\right)
$$

It should be noted that this is the standard target criterion for monetary policy in closed economy analyses which ignore fiscal policy (see, for example, Woodford (2003)). Accordingly, integrating this criterion forward in time has the implication that the ECB will seek to return the price level to base following any shocks. It is this commitment that allows commitment policy to achieve a better trade-off between output and inflation stabilisation than would be achieved under time-consistent policy.

Under discretion the ECB takes union-wide inflationary expectations as given such that the target criterion reduces to,

$$
\epsilon\left(\pi_{t}^{*}\right)=\left(y_{t}^{*, g}\right)
$$

and the ECB no longer seeks to return the price level to base follow shocks.

When we assume that the ECB simply takes the value of fiscal instruments as given and ignores the repercussions of its actions on debt (and any subsequent fiscal response) then we obtain the results shown in Figure 5. In this case, the union-wide debt correction is gradual under both discretion and commitment. The main difference between commitment and discretion lies in the inflation response where the ECB's commitment to return the price level to base has expectational benefits which significantly reduce the inflationary consequences of the debt shock. The welfare costs of ECB commitment and discretion are $0.0003037 \%$ and $0.000378 \%$ of steady-state consumption, respectively which is double the levels observed under the combination of ECB leadership and commitment, but remains a fraction of the level observed when the ECB recognises national government budget constraints, but cannot commit.

\subsection{Robustness to Steady-State Debt Levels}

In this sub-section we briefly explore the impact of varying the level of debt and the extent of price stickiness on our results above. In Figure 6 we outline the time consistent response to a union-wide debt shock when the ECB recognises the impact of its actions on debt and the national fiscal authorities. Here we find that at very low debt levels the rapid fiscal correction disappears as variations in real interest rates on very small debt stocks are not such a temptation for policymakers. Under other policy permutations, price stickiness affects results in same way as national policy. These policy experiments are summarised in Table 2 .

Table 2 - Summary of ECB Policy Experiments 


\begin{tabular}{|l|l|l|l|l|l|}
\hline Fig & Regime & Time Consistent? & $\frac{D e b t}{G D P}$ & Price Stickiness, $\theta$ & Debt Adjustment \\
\hline 5 & ECB Stackelberg Leader & Yes & $60 \%$ & 0.7 & Gradual \\
\hline & & No & $60 \%$ & 0.7 & Rapid \\
\hline 6 & ECB ignores Fiscal Policy & Yes & $60 \%$ & 0.7 & Gradual \\
\hline & & No & $60 \%$ & 0.7 & Gradual \\
\hline 7 & ECB Stackelberg Leader & Yes & $15 \%$ & 0.7 & Gradual \\
\hline & & & $50 \%$ & 0.7 & Rapid \\
\hline & & & $80 \%$ & 0.7 & Rapid \\
\hline
\end{tabular}

\section{Conclusions}

In this paper we explored the impact of time-consistent national fiscal policies on the ECB's monetary policy. We found that, in contrast to the closed economy or flexible exchange rate cases, national fiscal policies in a monetary union would act to gradually stabilise national government debt stocks following shocks through a combination of tax increases and government spending cuts. Despite the fact that national fiscal policies were essentially sound, in the sense that they steadily stabilised debt following shocks, the ECB would attempt to utilise its policy instrument to influence union-wide average government debt levels. Under commitment this effect was slight, but when constrained to be time-consistent, the ECB would strongly adjust policy to rapidly adjust unionwide debt. Essentially, under commitment the ECB resists the temptation to introduce policy surprises to reduce the need for national governments to make the costly fiscal corrections. Under discretion, this temptation results in a very rapid debt correction through changes in debt service costs, the union-wide tax base and the induced national fiscal response to ECB policy. It is important to note that the ECB does not behave in this way because of potentially reckless behaviour on the part of the national fiscal authorities. Nor does it have an explicit debt target. In fact, the ECB would only stop rapidly stabilising the union-wide debt stock if its relative weight on inflation was increased such that it behaved in a manner close to a strict inflation targeter.

This has another implication for optimal ECB policy. If the ECB cannot commit (even if it may be conservative) then it should not maximise union wide welfare in the usual way. Instead, welfare would be improved by ensuring the ECB followed the conventional assignment and ignored union wide debt and the national fiscal response to it.

\section{References:}

- Aiyagari, S. R., A. Marcet, T. J. Sargent and J. Seppala (2002), "Optimal Taxation with State-Contingent Debt", Journal of Political Economy, Vol. 110 (6), pp 1220-1254.

- Barro, R. J. (1979), "On the Determination of the Public Debt," Journal of Political Economy, 64, 93-110. 
- Beetsma, R. M. W. J. and H. Jensen (2004), "Mark-up Fluctuations and Fiscal Policy Stabilisation in a Monetary Union", Journal of Macroeconomics, 26, pp 357-376

- Benigno, P. and M. Woodford (2003), "Optimal Monetary and Fiscal Policy: A Linear Quadratic Approach", NBER Macroeconomics Annual.

- Benigno, P. and M. Woodford (2006), "Optimal Taxation in an RBC model: a linear-quadratic approach", Journal of Economic Dynamics and Control, 30, pp 1445-1489.

- Calvo, G. (1983), "Staggered Prices in a Utility Maximising Framework", Journal of Monetary Economics, 12(3), 383-398.

- Canzoneri, M. B., R. E. Cumby and B. T. Diba (2001), "Fiscal Discipline and Exchange Rate Systems", 111, pp 667-690.

- Clarida, R. M. Gertler and J. Gali (1999), "The Science of Monetary Policy: A New Keynesian Perspective', Journal of Economic Perspectives.

- Clarida, R. M. Gertler and J. Gali (2001), "Optimal Monetary Policy in Open Versus Closed Economies: An Integrated Approach" . American Economic Review Papers and Proceedings, 91 (2), pp. 248-252.

- Currie, D. and P. Levine (1993), "Rules, Reputation and Macroeconomic Policy Coordination", Cambridge University Press, Cambridge.

- Diaz-Gimenez, J., G. Giovannetti, R. Marimon anbd P. Teles (2008), "Nominal Debt as a Burden on Monetary Policy", Review of Economic Dynamics, 11, pp 493-514.

- Ellison, M. and N. Rankin (2007), "Optimal Monetary Policy when LumpSum Taxes are Unavailable: A Reconsideration of the outcomes under Commitment and Discretion", Journal of Economic Dynamics and Control, 31(1), pp 219-243.

- Erceg, C. J., D. W. Henderson and A. T. Levin (2000), "Optimal Monetary Policy with Staggered Wage and Price Contracts", Journal of Monetary Economics, Vol. 46, pp 281-313.

- Gali, J. and T. Monacelli (2005), "Monetary Policy and Exchange Rate Volatility in a Small Open Economy", Vol. 75, pp 707-734.

- Gali, J. and T. Monacelli (2008), "Optimal Fiscal Policy in a Monetary Union", Journal of International Economics, 76(1), pp 116-133.

- Herr, B. and A. Maussner (2009), "Dynamic General Equilibrium Modeling", 2nd Edition, Pub. Springer, Berlin.

- Kirsanova, T. and S Wren-Lewis (2004), "Optimal Fiscal Feedback in an Economy with Inflation Persistence", mimeograph, University of Exeter. 
- Leith, C. and J. Malley (2005), "Estimated General Equilibrium Models for the Analysis of Monetary Policy in the US and Europe", European Economic Review, 49(8), pp 2137-2159.

- Leith, C. and S. Wren-Lewis (2005), "Compatibility Between Monetary and Fiscal Policy Under EMU", European Economic Review, vol 50(6), pp $1529-1556$.

- Leith, C. and S. Wren-Lewis (2007), "Fiscal Sustainability in a New Keynesian Model", mimeograph, University of Glasgow.

- Leith, C. and S. Wren-Lewis (2007), "Countercyclical Fiscal Policy - Which Instrument is Best?", mimeograph, University of Glasgow.

- Lombardo, G. and A. Sutherland (2004), "Monetary and Fiscal Interactions in Open Economies", Journal of Macroeconomics, 26, 319-348.

- Lucas, R. E. and N. Stokey (1983), "Optimal monetary and fiscal policy in an economi without capital", Journal of Monetary Economics, 12, pp $55-93$.

- Nicolini, J. P. (1998), "More on the time inconsistency of optimal monetary policy", Journal of Monetary Economics, 41, pp 333-350.

- Oudis, G. and J. Sachs (1985), "International Policy Coordination in Dynamic Macroeconomic Models", in W. H. Buiter and R. C. Marston, eds, International Economic Policy Coordination, Cambridge University Press, Cambridge.

- Schmitt-Grohe, S. and M. Uribe (2004), "Optimal Monetary and Fiscal Policy under Sticky Prices", Journal of Economic Theory,114, February 2004, pp 198-230.

- Smets, F. and R. Wouters (2005), "Comparing shocks and frictions in US and euro area business cycles: a Bayesian DSGE Approach", Journal of Applied Econometrics, Volume 20, Issue 2, pp 161 - 183 .

- Soderlind, P. (1999), "Solution and Estimation of RE Macromodels with Optimal Policy", European Economic Review, 43, pp 813-823.

- Woodford, M. (2003), Interest and Prices, Princeton University Press. 


\section{Appendix 1 - Intratemporal Consumption Alloca- tion}

Households must first decide how to allocate a given level of expenditure across the various goods that are available. They do so by adjusting the share of a particular good in their consumption bundle to exploit any relative price differences - this minimises the costs of consumption. Optimisation of expenditure for any individual good implies the demand functions given below,

$$
\begin{aligned}
C_{H}(j) & =\left(\frac{P_{H}(j)}{P_{H}}\right)^{-\epsilon} C_{H} \\
C_{i}(j) & =\left(\frac{P_{i}(j)}{P_{i}}\right)^{-\epsilon} C_{i}
\end{aligned}
$$

where we have price indices given by

$$
\begin{aligned}
P_{H} & =\left(\int_{0}^{1} P_{H}(j)^{1-\epsilon} d j\right)^{\frac{1}{1-\epsilon}} \\
P_{i} & =\left(\int_{0}^{1} P_{i}(j)^{1-\epsilon} d j\right)^{\frac{1}{1-\epsilon}}
\end{aligned}
$$

It follows that

$$
\begin{gathered}
\int_{0}^{1} P_{H}(j) C_{H}(j) d j=P_{H} C_{H} \\
\int_{0}^{1} P_{i}(j) C_{i}(j) d j=P_{i} C_{i}
\end{gathered}
$$

Optimisation across imported goods by country implies

$$
C_{i}=\left(\frac{P_{i}}{P_{F}}\right)^{-\eta} C_{F}
$$

where

$$
P_{F}=\left(\int_{0}^{1} P_{i}^{1-\eta} d i\right)^{\frac{1}{1-\eta}}
$$

This implies

$$
\int_{0}^{1} P_{i} C_{i} d i=P_{F} C_{F}
$$

Optimisation between imported and domestically produced goods implies

$$
\begin{aligned}
P_{H} C_{H} & =(1-\alpha) P C \\
P_{F} C_{F} & =\alpha P C
\end{aligned}
$$

where

$$
P=P_{H}^{1-\alpha} P_{F}^{\alpha}
$$

is the consumer price index (CPI). 


\section{Appendix 2 - Price and Exchange Rate Identi- ties}

The effective terms of trade are given by

$$
S=\frac{P_{F}}{P_{H}}
$$

which can be combined with the definition of consumer prices, (78), and in logged first-difference form implies,

$$
\pi_{t}=\pi_{H, t}+\alpha\left(s_{t}-s_{t-1}\right)
$$

There is assumed to be free-trade in goods, such that the law of one price holds for individual goods at all times. This implies,

$$
P_{i}(j)=\varepsilon_{i} P_{i}^{i}(j)
$$

where $\varepsilon_{i}$ is the bilateral nominal exchange rate and $P_{i}^{i}(j)$ is the price of county i's good j expressed in terms of country i's currency. Aggregating across goods this implies,

$$
P_{i}=\varepsilon_{i} P_{i}^{i}
$$

where $P_{i}^{i}=\left(\int_{0}^{1} P_{i}^{i}(j)^{1-\epsilon} d j\right)^{\frac{1}{1-\epsilon}}$.

From the definition of $P_{F}$ we have, in log-linearised form,

$$
p_{F}=e+p^{*}
$$

where $e=\int_{0}^{1} e_{i} d i$ is the log of the nominal effective exchange rate, $p_{i}^{i}$ is the logged domestic price index for country $\mathrm{i}$, and $p^{*}=\int_{0}^{1} p_{i}^{i} d i$ is the $\log$ of the world price index. For the world as a whole there is no distinction between consumer prices and the domestic (world) price level.

Combining the definition of the terms of trade and the result just obtained gives

$$
\begin{aligned}
s & =p_{F}-p_{H} \\
& =e+p^{*}-p_{H}
\end{aligned}
$$

Now consider the link between the terms of trade and the real exchange rate. (Note that although we have free trade and the law of one price holds for individual goods, our economies do not exhibit PPP since there is a home bias in the consumption of home and foreign goods. PPP only holds if we eliminate this home bias and assume $\alpha=1$ since this implies that the share of home goods in consumption is the same as any other country's i.e. infinitesimally small.) The bilateral real exchange rate is defined as,

$$
Q_{i}=\frac{\varepsilon_{i} P^{i}}{P}
$$


where $P^{i}$ and $P$ are the two countries respective CPI price levels. In logged form we can define the real effective exchange rate as,

$$
\begin{aligned}
q_{t} & =\int_{0}^{1}\left(e_{i}+p^{i}-p\right) d i \\
& =e+p^{*}-p \\
& =s+p_{H}-p \\
& =(1-\alpha) s
\end{aligned}
$$

\section{Appendix 3 - Government Debt}

Recall the home country consumer's budget constraint,

$$
P_{t} C_{t}+Q_{t, t+1} D_{t+1} \leq \Pi_{t}+D_{t}+W_{t} N_{t}\left(1-\tau_{t}\right)-T_{t}
$$

There is a unique stochastic discount factor which has the property,

$$
A_{t}=E_{t}\left[Q_{t, t+1} D_{t+1}\right]
$$

where $A_{t}$ is the end-of period nominal value of the household's portfolio of assets. If the household chooses to hold only risk-less one period bonds then this condition becomes,

$$
D_{t+1}=R_{t} A_{t}
$$

However, households will not only hold government bonds as they will wish to hold a complete set of contingent assets. The wealth $D_{t+1}$ being transferred into the next period satisfies the bound,

$$
D_{t+1} \geq-\sum_{T=t+1}^{\infty} E_{t+1}\left[Q_{t+1, T}\left(\Pi_{T}+W(k)_{T} N(k)_{T}\left(1-\tau_{T}\right)-T_{T}\right)\right]
$$

with certainty, no matter what state of the world emerges. These series of borrowing constraints and flow budget constraints then defines the intertemporal budget constraint. We rule out no-Ponzi schemes which amounts to,

$$
\sum_{T=t}^{\infty} E_{t}\left[Q_{t, T}\left(\Pi_{T}+W(k)_{T} N(k)_{T}\left(1-\tau_{T}\right)-T_{T}\right)\right]<\infty
$$

at each point in time across all possible states of the world. These can be combined to yield the intertemporal budget constraint (see Woodford, 2003, Chapter 2, page 69),

$$
\sum_{T=t}^{\infty} E_{t}\left[P_{T} C_{T}\right] \leq D_{t}+\sum_{T=t}^{\infty} E_{t}\left[Q_{t, T}\left(\Pi_{T}+W(k)_{T} N(k)_{T}\left(1-\tau_{T}\right)-T_{T}\right)\right]
$$

Note what this implies. Aggregating over households would, in a closed economy, allow us to show the equivalence of private and public sector budget constraints. 
Noting the equivalence between factor incomes and national output,

$$
P_{H} Y=W N+\Pi-\varkappa W N+\tau^{r} P_{H} Y_{H}
$$

we can rewrite the home country's budget constraint as,

$$
D_{t}=-\sum_{T=t}^{\infty} E_{t}\left[Q_{t, T}\left(P_{H, T} Y_{T}-P_{T} C_{T}-W_{T} N_{T}\left(\tau_{T}-\varkappa\right)-\tau_{T}^{r} P_{H, T} Y_{H, T}-T_{T}\right)\right]
$$

Recall the goods market clearing condition in the home economy,

$$
Y=(1-\alpha) \frac{P C}{P_{H}}+\alpha \int_{0}^{1}\left(\frac{\varepsilon_{i} P^{i} C^{i}}{P_{H}}\right) d i+G
$$

Similar conditions exist in economy $j$,

$$
Y^{j}=(1-\alpha) \frac{P^{j} C^{j}}{P_{j}}+\alpha \int_{0}^{1}\left(\frac{\varepsilon_{i} P^{i} C^{i}}{\varepsilon_{j} P_{j}}\right) d i+G^{j}
$$

This can then be aggregated across member states,

$$
\begin{aligned}
\int_{0}^{1} \varepsilon_{j} P_{j} Y^{j} d j & =(1-\alpha) \int_{0}^{1} \varepsilon_{j} P^{j} C^{j} d j+\alpha \int_{0}^{1} \int_{0}^{1}\left(\varepsilon_{i} P^{i} C^{i}\right) d i d j+\int_{0}^{1} \varepsilon_{j} P_{j} G^{j} d j \\
& =(1-\alpha) \int_{0}^{1} \varepsilon_{j} P^{j} C^{j} d j+\alpha \int_{0}^{1}\left(\varepsilon_{i} P^{i} C^{i}\right) d i+\int_{0}^{1} \varepsilon_{j} P_{j} G^{j} d j \\
& =\int_{0}^{1} \varepsilon_{j} P^{j} C^{j} d j+\int_{0}^{1} \varepsilon_{j} P_{j} G^{j} d j
\end{aligned}
$$

Integrating the budget constraints across economies and using this global market clearing condition yields the intertemporal budget constraint for the union as a whole,

$$
\int \varepsilon_{i} D_{t}^{i} d i=-\sum_{T=t}^{\infty} E_{t}\left[Q_{t, T}\left(\int_{0}^{1}\left(P_{i, T} G_{T}^{i}-W_{T}^{i} N_{T}^{i}\left(\tau_{T}^{i}-\varkappa_{i}\right)-T_{T}^{i}\right) d i\right)\right]
$$

where $\int \varepsilon_{i} D_{t}^{i} d i$ is the aggregate level of the national debt stocks. With global market clearing in asset markets the series of national budget constraints imply that the only public-sector intertemporal budget constraint in our model is a global constraint. However, as discussed in the main text, we impose, as an external constraint created within the institutions of EMU or International Risk Sharing, a national government budget constraint of the form,

$$
D_{t}^{i}=-\sum_{T=t}^{\infty} E_{t}\left[Q_{t, T}\left(P_{i, T} G_{T}^{i}-W_{T}^{i} N_{T}^{i}\left(\tau_{T}^{i}-\varkappa_{i}\right)-T_{T}^{i}\right)\right]
$$

In order to support the assumption that the steady-state level of output is efficient (which facilitates the derivation of welfare functions below) an obvious 
assumption to make is that lump-sum taxation is used to finance the steady-state subsidy (which offsets, in steady-state, the distortions caused by distortionary taxation and imperfect competition in price setting). We shall then assume that lump-sum taxation cannot be used to alter this subsidy or to finance any other government activities, including the kind of spending and distortionary tax adjustments as stabilisation measures we are interested in. This implies that $W_{T}^{i} N_{T}^{i} \varkappa_{i}=T_{T}^{i}$ in all our economies at all points in time, allowing us to simplify the budget constraint to,

$$
B_{t-1}^{i} R_{t-1}=-\sum_{T=t}^{\infty} E_{t}\left[Q_{t, T}\left(P_{i, T} G_{T}^{i}-W_{T}^{i} N_{T}^{i} \tau_{T}^{i}\right)\right]
$$

i.e. distortionary taxation and spending adjustments are required to service government debt as well as stabilise the economy. This defines the basic tradeoff facing policy makers in utilising these instruments.

The national flow budget constraint,

$$
\frac{b_{t}^{i}}{R_{t}}=\frac{P_{i, t-1}}{P_{i, t}} b_{t-1}^{i}+G_{t}^{i}-\frac{W_{t}^{i}}{P_{i, t}} N_{t}^{i} \tau_{t}^{i}
$$

can be log-linearised as,

$$
\beta\left(\widehat{b}_{t}^{i}-\widehat{r}_{t}\right)=\left(\widehat{b}_{t-1}^{i}-\pi_{i, t}\right)+\frac{\bar{G}^{i}}{\bar{B}^{i}} \ln \frac{G_{t}^{i}}{\bar{G}^{i}}-\frac{\bar{\tau} \bar{W}^{i} \bar{N}^{i}}{\bar{B}^{i}}\left(\widehat{r w}_{t}^{i}+\widehat{n}_{t}^{i}+\widehat{\tau}_{t}^{i}\right)
$$

where $\widehat{x}_{t}=\ln \left(x_{t} / \bar{x}\right)$. Using the labour supply function (11) to eliminate real product wages, along with the production function,

$\beta\left(\widehat{b}_{t}^{i}-r_{t}\right)=\left(\widehat{b}_{t-1}^{i}-\pi_{i, t}\right)+\frac{\bar{G}^{i}}{\bar{B}^{i}} \ln \frac{G_{t}^{i}}{\bar{G}^{i}}-\frac{\bar{\tau} \bar{W}^{i} \bar{N}^{i}}{\bar{B}^{i}}\left((1+\varphi)\left(\widehat{y}_{t}^{i}-a_{t}^{i}\right)+\widehat{y}_{t}^{i}-\widehat{g}_{t}^{i}+\frac{1}{1-\tau} \tau_{t}^{i}\right)$

Note, however, that $g_{t}$ in the model is defined as, $\ln \left(1-\frac{G}{Y}\right)$. This implies, to a first order, that,

$$
\begin{aligned}
\ln G^{i} & =\ln \left(\frac{G^{i}}{Y^{i}}\right)+\ln \left(Y^{i}\right) \\
& =\ln \left(1-\exp \left(-g^{i}\right)\right)+y^{i} \\
& =\frac{1-\gamma^{i}}{\gamma^{i}} g^{i}+y^{i}
\end{aligned}
$$

where $\gamma^{i, n}=G^{i} / Y^{i}$. Introducing this to the budget constraint, and collecting terms,

$$
\begin{aligned}
\beta\left(\widehat{b}_{t}^{i}-r_{t}\right)= & \left.\left(\widehat{b}_{t-1}^{i}-\pi_{i, t}\right)+\left(\frac{\bar{G}^{i}}{\bar{B}^{i}} \frac{1-\gamma^{i}}{\gamma^{i}}+\frac{\bar{\tau} \bar{W}^{i} \bar{N}^{i}}{\bar{B}^{i}}\right) \widehat{g}_{t}^{i}\right)-(\bar{R}-1) \widehat{y}_{t}^{i} \\
& -\frac{\bar{\tau} \bar{W}^{i} \bar{N}^{i}}{\bar{B}^{i}}\left((1+\varphi)\left(\widehat{y}_{t}^{i}-a_{t}^{i}\right)+\frac{1}{1-\tau} \tau_{t}^{i}\right)
\end{aligned}
$$




\section{Appendix 4 - Price Setting}

$t$,

Recall the optimal price set by firms that are able to reset prices in period

$$
\bar{P}_{H, t}=\frac{\sum_{s=0}^{\infty}(\theta)^{s} Q_{t, t+s}\left[\epsilon \frac{W_{t+s}}{P_{t+s}} P_{H, t+s}^{\epsilon} \frac{Y_{t+s}}{A_{t+s}}\right]}{\sum_{s=0}^{\infty}(\theta)^{s} Q_{t, t+s}\left[(\epsilon-1)\left(1-\tau_{t+s}^{r}\right) P_{t+s}^{-1} P_{H, t+s}^{\epsilon} Y_{t+s}(1-\chi)\right]}
$$

Note that in equilibrium,

$$
\beta^{s}\left(\frac{C_{t}}{C_{t+s}}\right)\left(\frac{P_{t}}{P_{t+s}}\right)=Q_{t, t+s}
$$

Accordingly, the expression for the optimal price can be re-written as,

$$
\bar{P}_{H, t}=\frac{\sum_{s=0}^{\infty}(\theta \beta)^{s} \frac{C_{t} P_{t}}{C_{t+s} P t+s}\left[\epsilon \frac{W_{t+s}}{P_{t+s}} P_{H, t+s}^{\epsilon} \frac{Y_{t+s}}{A_{t+s}}\right]}{\sum_{s=0}^{\infty}(\theta \beta)^{s} \frac{C_{t} P_{t}}{C_{t+s} P t+s}\left[(\epsilon-1)\left(1-\tau_{t+s}^{r}\right) P_{t+s}^{-1} P_{H, t+s}^{\epsilon} Y_{t+s}(1-\chi)\right]}
$$

After allowing the mark-up to be time varying due to mark-up shocks, this can be log-linearised as,

$$
\bar{p}_{H, t}=(1-\theta \beta) E_{t}\left(\sum_{s=0}^{\infty}\left(\theta_{w} \beta\right)^{s}\left[-a_{t+s}+w_{t+s}-\ln \left(1-\tau_{t+s}^{r}\right)-v_{t}+\ln \left(\mu_{t}\right)\right]\right)
$$

where $\bar{p}_{H, t}$ is the log of the optimal price set by those firms that were able to set price in period $\mathrm{t}$, and $v=-\ln (1-\chi)$. Quasi-differencing this expression yields,

$$
\frac{1}{1-\theta \beta} \bar{p}_{H, t}=\frac{1}{1-\theta \beta} \theta \beta E_{t} \bar{p}_{H, t+1}-a_{t}+w_{t}-\ln \left(1-\tau_{t}^{r}\right)-v_{t}+\ln \left(\mu_{t}\right)
$$

While domestic prices evolve according to,

$$
P_{H, t}=\left[(1-\theta) \bar{P}_{H, t}^{1-\epsilon}+\theta P_{H, t-1}^{1-\epsilon}\right]^{\frac{1}{1-\epsilon}}
$$

This can be log-linearised as,

$$
p_{H, t}=(1-\theta) \bar{p}_{H, t}+\theta p_{H, t-1}
$$

Solving for $\bar{p}_{H, t}$ and substituting into the expression for quasi-differenced optimal price yields,

$$
\begin{aligned}
\frac{1}{1-\theta \beta}\left(\frac{p_{H, t}}{1-\theta}-\frac{\theta p_{H, t-1}}{1-\theta}\right)= & \frac{1}{1-\theta \beta} \theta \beta\left(\frac{E_{t} p_{H, t+1}}{1-\theta}-\frac{\theta p_{H, t}}{1-\theta}\right) \\
& -a_{t}+w_{t}-\ln \left(1-\tau_{t}^{r}\right)-v_{t}+\ln \left(\mu_{t}\right)
\end{aligned}
$$


This can be solved as,

$$
\pi_{H, t}=\beta E_{t} \pi_{H, t+1}+\frac{(1-\theta \beta)(1-\theta)}{\theta}\left(m c_{t}+\ln \left(\mu_{t}\right)\right)
$$

where $m c_{t}=-a_{t}+w_{t}-p_{H, t}-\ln \left(1-\tau_{t}^{s}\right)-v_{t}$ are the real log-linearised marginal costs of production. In the absence of sticky prices profit maximising behaviour implies, $m c=-\ln (\mu)$.

\section{Appendix 5 - Gap variables}

Define the natural level of $(\log )$ output $y^{n}$ as the level that would occur in the absence of nominal inertia and conditional on the optimal choice of government spending, the steady-state tax rates and the actual level of world output. Define the output gap as,

$$
\begin{aligned}
y_{t}^{i, g} & =y_{t}^{i}-y_{t}^{i, n} \\
& =\widehat{y}_{t}^{i}-\widehat{y}_{t}^{i, n}
\end{aligned}
$$

With flexible prices and wages we have $m c_{t}^{i, n}=-\mu_{t}^{i}$. Substituting into the expression for $m c_{t}^{i}$ implies,

$$
y_{t}^{i, n}=a_{t}^{i}+g_{t}^{i, n} /(1+\varphi)+\left(v+\ln (1-\bar{\tau})-\ln \left(\mu_{t}^{i}\right)\right) /(1+\varphi)
$$

Substituting this into the Phillips curve gives,

$$
\pi_{i, t}=\beta E_{t}\left\{\pi_{i, t+1}\right\}+\lambda\left[(1+\varphi) y_{t}^{i, g}-g_{t}^{i, g}+\frac{\tau}{1-\tau} \tau_{t}^{i, g}\right]
$$

where $\widehat{\mu}_{t}^{i}=\ln \left(\mu_{t}^{i} / \bar{\mu}\right)$ is the price mark-up shock and the tax gap as been defined so as to eliminate the effects of the mark-up shock on inflation, $\frac{\tau}{1-\tau} \tau_{t}^{i, n}=\mu_{t}^{i}$.

We can write (??) for gap variables as

$$
y_{t}^{i, g}=y_{t}^{i}-y_{t}^{i, n}=E_{t}\left\{y_{t+1}^{i, g}\right\}-\left(r_{t}-E_{t}\left\{\pi_{i, t+1}\right\}-r_{t}^{i, n}\right)-E_{t}\left\{g_{t+1}^{i, g}-g_{t}^{i, g}\right\}
$$

where $r_{t}^{i, n}=\rho+E_{t}\left\{y_{t+1}^{i, n}-y_{t}^{i, n}\right\}-E_{t}\left\{g_{t+1}^{i, n}-g_{t}^{i, n}\right\}$. Note that, given (116), the real natural rate of interest depends - like natural output - only on the productivity shock, the steady-state levels of distortionary taxation and the optimal level of government spending.

We also have the budget constraint in gap form,

$$
\begin{aligned}
\beta\left(\widehat{b}_{t}^{i}-r_{t}\right)= & \left(\widehat{b}_{t-1}^{i}-\pi_{i, t}\right)+\left(\frac{\bar{G}^{i}}{\bar{B}^{i}} \frac{1-\gamma^{i}}{\gamma^{i}}+\frac{\bar{\tau}^{i} \bar{N}^{i}}{\bar{B}^{i}}\right) g_{t}^{i, g} \\
& -(\bar{R}-1) y_{t}^{i, g}-\frac{\bar{\tau} \bar{W}^{i} \bar{N}^{i}}{\bar{B}^{i}}\left((1+\varphi)\left(y_{t}^{i, g}\right)+\frac{1}{1-\tau} \tau_{t}^{i, g}\right) \\
& -(\bar{R}-1) a_{t}^{i}+\frac{\bar{W}^{i} \bar{N}^{i}}{\bar{B}^{i}} \mu_{t}^{i}
\end{aligned}
$$


where we have again used the definition $\frac{\tau}{1-\tau} \tau_{t}^{i, n}=\mu_{t}$ is the efficient tax rate which eliminates the costs imposed by fluctuations in firms' desired mark-up. We can eliminate the term in the interest rate using the aggregate consumption Euler equation for the union as a whole,

$$
r_{t}=-\widehat{c}_{t}^{*}+E_{t}\left\{\widehat{c}_{t+1}^{*}\right\}+E_{t}\left\{\pi_{t+1}^{*}\right\}
$$

Finally the evolution of national competitiveness can be written in gap form,

$$
\Delta y_{t}^{i, g}=\Delta g_{t}^{i, g}+\Delta c_{t}^{*, g}+\pi_{t}^{*}-\pi_{i, t}-\Delta a_{t}^{i}+\Delta a_{t}^{*}
$$




\section{Appendix 6 - Derivation of Union and National Welfare}

The measure of welfare which we shall seek to approximate is based on an aggregate of household utility,

$$
\ln C_{t}+\chi \ln G_{t}-\frac{\left(N_{t}\right)^{1+\varphi}}{1+\varphi}
$$

The first term can be expanded as

$$
\begin{aligned}
c & =c^{n}+c^{g} \\
& =c^{n}+\alpha \int_{0}^{1} c^{g, j} d j+(1-\alpha)\left(y^{g}-g^{g}\right)
\end{aligned}
$$

Before considering the second term we need to note the following general result relating to second order approximations,

$$
\frac{Y_{t}-Y}{Y_{t}}=y_{t}+\frac{1}{2} y_{t}^{2}+o\left(\|a\|^{3}\right)
$$

where $o\left(\|a\|^{3}\right)$ represents terms that are of order higher than 3 in the bound $\|a\|$ on the amplitude of the relevant shocks. This will be used in various places in the derivation of welfare.

Now consider the second order approximation to the second term for an individual household can be written as,

$$
\frac{N^{1+\varphi}}{1+\varphi}=\frac{\left(N^{n}\right)^{1+\varphi}}{1+\varphi}+\left(N^{n}\right)^{1+\varphi}\left\{n^{g}+\frac{1}{2}(1+\varphi)\left(n^{g}\right)^{2}\right\}+o\left(\|a\|^{3}\right)
$$

Now we need to relate the labour input gap to the output gap and a measure of price dispersion. Aggregating the individual firms' demand for labour yields,

$$
N=\left(\frac{Y}{A}\right) \int_{0}^{1}\left(\frac{P_{H}(i)}{P_{H}}\right)^{-\epsilon} d i
$$

It can be shown that (see $\mathrm{GM}(2006))$

$$
\begin{aligned}
n^{g} & =y^{g}+\ln \left[\int_{0}^{1}\left(\frac{P_{H}(i)}{P_{H}}\right)^{-\epsilon} d i\right] \\
& =y^{g}+\frac{\epsilon}{2} \operatorname{var}_{i}\left\{p_{H}(i)\right\}+o\left(\|a\|^{3}\right)
\end{aligned}
$$

so we can write

$$
\begin{aligned}
\frac{N^{1+\varphi}}{1+\varphi}= & \frac{\left(N^{n}\right)^{1+\varphi}}{1+\varphi}+\left(N^{n}\right)^{1+\varphi}\left\{y^{g}+\frac{1}{2}\left(y^{g}\right)^{2}(1+\varphi)\right. \\
& \left.+\frac{\epsilon}{2} \operatorname{var}_{i}\left\{p_{H}(i)\right\}\right\}+o\left(\|a\|^{3}\right)
\end{aligned}
$$


The term in $\mathrm{G}$ can be expanded as

$$
\begin{aligned}
\ln G & =\ln \left(\frac{G}{Y}\right)+y^{g}+t i p \\
& =\ln (1-\exp (-g))+y^{g}+t i p \\
& =\frac{1-\gamma^{n}}{\gamma^{n}} g^{g}-\frac{1}{2} \frac{1-\gamma^{n}}{\left(\gamma^{n}\right)^{2}}\left(g^{g}\right)^{2}+y^{g}+t i p+o\left(\|a\|^{3}\right)
\end{aligned}
$$

where $\gamma^{n}=G^{n} / Y^{n}$. We can then write

$$
\begin{aligned}
\chi \ln G_{t} & =\frac{1-\gamma^{n}}{\gamma^{n}} \ln G_{t} \\
& =g_{t}^{g}-\frac{1}{2 \gamma^{n}}\left(g_{t}^{g}\right)^{2}+\chi y^{g}+t i p+o\left(\|a\|^{3}\right)
\end{aligned}
$$

Using these expansions, individual utility can be written as

$$
\begin{aligned}
\ln C_{t}+\chi \ln G_{t}-\frac{N_{t}^{1+\varphi}}{1+\varphi}= & c_{t}^{n}+\alpha \int_{0}^{1} c_{t}^{g, j} d j+(1-\alpha)\left(y_{t}^{g}-g_{t}^{g}\right)+ \\
& g_{t}^{g}-\frac{1}{2 \gamma^{n}}\left(g_{t}^{g}\right)^{2}+\chi y^{g} \\
& -\left[\frac{\left(N^{n}\right)^{1+\varphi}}{1+\varphi}+\left(N^{n}\right)^{1+\varphi}\left\{y_{t}^{g}+\frac{1}{2}\left(y_{t}^{g}\right)^{2}(1+\varphi)\right.\right. \\
& \left.+\frac{\epsilon}{2} \operatorname{var}_{i}\left\{p_{H, t}(i)\right\}\right]+\operatorname{tip}+O[3]
\end{aligned}
$$

Now, adding natural terms to tip and if we have an optimal subsidy, then

$$
N^{n}=(1+\chi)^{\frac{1}{1+\psi}}
$$

so we can simplify this as

$$
\begin{aligned}
\ln C_{t}+\chi_{t} \ln G_{t}-\frac{N_{t}^{1+\varphi}}{1+\varphi}= & \alpha \int_{0}^{1} c_{t}^{j, g} d j-\alpha\left(y_{t}^{g}-g_{t}^{g}\right)-\frac{1}{2 \gamma^{n}}\left(g_{t}^{g}\right)^{2} \\
& -(1+\chi)\left\{\frac{1}{2}\left(y_{t}^{g}\right)^{2}(1+\varphi)\right. \\
& +\frac{\epsilon}{2} \operatorname{var}_{i}\left\{p_{H}, t(i)\right\}+t i p+O[3]
\end{aligned}
$$

Total individual welfare in country $i$ is therefore given by

$$
\begin{aligned}
\Gamma^{i}= & \sum_{t=0} \beta^{t}\left[-\alpha\left(y_{t}^{i, g}-g_{t}^{i, g}\right)+\alpha \int_{0}^{1} c_{t}^{j, g} d j\right. \\
& -\frac{(1+\chi)}{2}\left(\left(y_{t}^{i, g}\right)^{2}(1+\varphi)+\frac{1}{\chi}\left(g_{t}^{i, g}\right)^{2}+\operatorname{evar}_{l}\left\{p_{i, t}(l)\right\}\right] \\
& +t i p+O[3]
\end{aligned}
$$

utilising the fact that $1-\frac{G^{n}}{Y^{n}}=1-\gamma^{n}=\frac{1}{1+\chi}$. 
Woodford (2003, Chapter 6) shows that

$$
\sum \beta^{t} \operatorname{var}_{l}\left\{p_{i, t}(l)\right\}=\frac{1}{\lambda} \sum \beta^{t} \pi_{i, t}^{2}
$$

where we use the expression of the sum to $\mathrm{n}$ terms of a geometric series to write,

$$
\begin{aligned}
\Gamma^{i}= & \sum_{t=0} \beta^{t}\left[-\alpha\left(y_{t}^{i, g}-g_{t}^{i, g}\right)+\alpha \int_{0}^{1} c_{t}^{j, g} d j\right. \\
& -\frac{(1+\chi)}{2}\left(\left(y_{t}^{i, g}\right)^{2}(1+\varphi)+\frac{1}{\chi}\left(g_{t}^{i, g}\right)^{2}+\frac{\epsilon}{\lambda} \pi_{i, t}^{2}\right] \\
& +t i p+o\left(\|a\|^{3}\right)
\end{aligned}
$$

This can be written as,

$$
\begin{aligned}
\Psi^{i}= & -\frac{(1+\chi)}{2} \sum_{t=0}^{\infty} \beta^{t}\left[\frac{\epsilon}{\lambda} \pi_{i, t}^{2}+(1+\varphi)\left(y_{t}^{i, g}+\frac{\alpha}{(1+\chi)(1+\varphi)}\right)^{2}+\frac{1}{\chi}\left(g_{t}^{i, g}-\frac{\alpha \chi}{(1+\varphi)(1+\chi)}\right)^{2}\right] \\
& +t i p+o\left(\|a\|^{3}\right)
\end{aligned}
$$

Notice that the expression for individual country welfare includes linear terms which are not present in the description of union-wide welfare described below. These arise from the desire of the national fiscal authority to raise their terms of trade relative to their trading partners. In aggregate this cannot happen, and so this desire is not reflected in the union-wide welfare function. Integrating over all economies, and utilising

$$
\int_{0}^{1}\left(y^{i, g}-c^{i, g}-g^{i, g}\right) d i=0
$$

we obtain

$$
\Gamma=-\frac{(1+\chi)}{2} \sum_{t=0} \beta^{t} \int_{0}^{1}\left[\frac{\epsilon}{\lambda} \pi_{i, t}^{2}+\left(y_{t}^{i, g}\right)^{2}(1+\varphi)+\frac{1}{\chi}\left(g_{t}^{i, g}\right)^{2}\right] d i+t i p+o\left(\|a\|^{3}\right)
$$

Welfare is the sum of quadratic terms in inflation (for both wages and prices), the output gap and the government spending gap in each country. 


\section{Appendix 7 - Matrix Representation of Model}

\section{(1)National Fiscal Policy Maker's problem}

The economy is described as,

$$
\left[\begin{array}{c}
\mathbf{x}_{1 t+1} \\
E_{t} \mathbf{x}_{2 t+1}
\end{array}\right]=\mathbf{A}\left[\begin{array}{c}
\mathbf{x}_{1 t} \\
\mathbf{x}_{2 t}
\end{array}\right]+\mathbf{B} \mathbf{u}_{t}+\left[\begin{array}{c}
\varepsilon_{t+1} \\
\mathbf{0}
\end{array}\right]
$$

where

$$
x_{t}=\left[\begin{array}{lllllllllll}
y_{t-1}^{i, g} & g_{t-1}^{i, g} & \widehat{b}_{t-1}^{i} & a_{t}^{i} & f b_{t}^{*} & f y_{t}^{*} & \tau_{t-1}^{i, g} & \pi_{i, t-1} & a_{t-1}^{i} & \varepsilon_{t} & \pi_{i, t}
\end{array}\right]^{\prime}
$$

$u_{t}=\left[\begin{array}{ll}g_{t}^{i, g} & \tau_{t}^{i, g}\end{array}\right]^{\prime}$ and the exogenous union-wide elements in the national economy's problem are defined as,

$$
\begin{aligned}
f b_{t}^{*} & =\beta r_{t}-\beta(1-\rho) a_{t}^{*} \\
& =\beta\left(-c_{t}^{*, g}+E_{t} c_{t+1}^{*, g}+E_{t} \pi_{t+1}^{*}\right)-\beta(1-\rho) a_{t}^{*}
\end{aligned}
$$

and,

$$
f y_{t}^{*}=\Delta c_{t}^{*, g}+\Delta a_{t}^{*}+\pi_{t}^{*}
$$

$\mathbf{A}=\mathbf{A} \mathbf{0}^{-1} \mathbf{A} \mathbf{1}$ and $\mathbf{B}=\mathbf{A} \mathbf{0}^{-1} \mathbf{B} \mathbf{1}$ where

$$
\begin{aligned}
& \mathbf{A 0}=\left[\begin{array}{ccccccccccc}
1 & -1 & 0 & 0 & 0 & 0 & 0 & 0 & 0 & 0 & 0 \\
0 & 1 & 0 & 0 & 0 & 0 & 0 & 0 & 0 & 0 & 0 \\
1 / \beta-1+\frac{\bar{\tau} \bar{N} \bar{w}}{\bar{B}}(1+\varphi) & -\left((1-\gamma) \frac{\bar{N}}{\bar{B}}+\frac{\bar{\tau} \bar{N} \bar{w}}{\bar{B}}\right) & \beta & 0 & 0 & 0 & \frac{\bar{\tau} \bar{N} \bar{w}}{(1-\bar{\tau}) \bar{B}} & 0 & 1 / \beta & 0 & 0 \\
0 & 0 & 0 & 1 & 0 & 0 & 0 & 0 & 0 & 0 & 0 \\
0 & 0 & 0 & 0 & 1 & 0 & 0 & 0 & 0 & 0 & 0 \\
0 & 0 & 0 & 0 & 0 & 1 & 0 & 0 & 0 & 0 & 0 \\
0 & 0 & 0 & 0 & 0 & 0 & 1 & 0 & 0 & 0 & 0 \\
0 & 0 & 0 & 0 & 0 & 0 & 0 & 1 & 0 & 0 & 0 \\
0 & 0 & 0 & 0 & 0 & 0 & 0 & 0 & 1 & 0 & 0 \\
0 & 0 & 0 & 0 & 0 & 0 & 0 & 0 & 0 & 1 & 0 \\
\lambda(1+\varphi) & -\lambda & 0 & 0 & 0 & 0 & \lambda \frac{\bar{\tau}}{(1-\bar{\tau})} & 0 & 0 & 0 & \beta
\end{array}\right] \\
& \mathbf{A} \mathbf{1}=\left[\begin{array}{ccccccccccc}
1 & -1 & 0 & -1 & 0 & 1 & 0 & 0 & 1 & 0 & -1 \\
0 & 0 & 0 & 0 & 0 & 0 & 0 & 0 & 0 & 0 & 0 \\
0 & 0 & 1 & 0 & 1 & 0 & 0 & 0 & 0 & 0 & -1 \\
0 & 0 & 0 & \rho & 0 & 0 & 0 & 0 & 0 & 1 & 0 \\
0 & 0 & 0 & 0 & 0 & 0 & 0 & 0 & 0 & 0 & 0 \\
0 & 0 & 0 & 0 & 0 & 0 & 0 & 0 & 0 & 0 & 0 \\
0 & 0 & 0 & 0 & 0 & 0 & 0 & 0 & 0 & 0 & 0 \\
0 & 0 & 0 & 0 & 0 & 0 & 0 & 0 & 0 & 0 & 1 \\
0 & 0 & 1 & 0 & 0 & 0 & 0 & 0 & 0 & 0 & 0 \\
0 & 0 & 0 & 0 & 0 & 0 & 0 & 0 & 0 & 0 & 0 \\
0 & 0 & 0 & 0 & 0 & 0 & 0 & 0 & 0 & 0 & 1
\end{array}\right] \mathbf{B 1}=\left[\begin{array}{cc}
0 & 0 \\
1 & 0 \\
0 & 0 \\
0 & 0 \\
0 & 0 \\
0 & 0 \\
0 & 1 \\
0 & 0 \\
0 & 0 \\
0 & 0 \\
0 & 0
\end{array}\right]
\end{aligned}
$$


The policy maker's objectives can be written as,

$$
J_{0}=E_{0} \sum_{t=0}^{\infty} \beta^{t}\left[\mathbf{x}_{t}^{\prime} \mathbf{Q} \mathbf{x}_{t}+2 \mathbf{x}_{t}^{\prime} \mathbf{U} \mathbf{u}_{t}+\mathbf{u}_{t}^{\prime} \mathbf{R} \mathbf{u}_{t}\right]
$$

where $\mathbf{Q}=(1+\varphi) \mathbf{A}_{1}^{\prime} \mathbf{A}_{1}+\left(\frac{1}{\chi}\right) \mathbf{A}_{2}^{\prime} \mathbf{A}_{2}+\frac{\varepsilon}{\lambda} \mathbf{A}_{8}^{\prime} \mathbf{A}_{8}, U=(1+\varphi) \mathbf{A}_{1}^{\prime} \mathbf{B}_{1}+\left(\frac{1}{\chi}\right) \mathbf{A}_{2}^{\prime} \mathbf{B}_{2}+$ $\frac{\varepsilon}{\lambda} \mathbf{A}_{8}^{\prime} \mathbf{B}_{8}$, and $\mathbf{R}=(1+\varphi) \mathbf{B}_{1}^{\prime} \mathbf{B}_{1}+\left(\frac{1}{\chi}\right) \mathbf{B}_{2}^{\prime} \mathbf{B}_{2}+\frac{\varepsilon}{\lambda} \mathbf{B}_{8}^{\prime} \mathbf{B}_{8}$ where $\mathbf{A}_{j}$ is the jth row of $\mathbf{A}$.

\section{(2)Monetary Leadership}

The union-wide economy is described as,

$$
\left[\begin{array}{c}
\mathbf{x}_{1 t+1} \\
E_{t} \mathbf{x}_{2 t+1}
\end{array}\right]=\mathbf{A}\left[\begin{array}{c}
\mathbf{x}_{1 t} \\
\mathbf{x}_{2 t}
\end{array}\right]+\mathbf{B} \mathbf{u}_{t}+\left[\begin{array}{c}
\varepsilon_{t+1} \\
\mathbf{0}
\end{array}\right]
$$

where

$$
x_{t}=\left[\begin{array}{llllllllll}
y_{t-1}^{*, g} & g_{t-1}^{*, g} & \widehat{b}_{t-1}^{*} & a_{t}^{*} & \tau_{t-1}^{*, g} & \pi_{t-1}^{*} & a_{t-1}^{*} & \varepsilon_{t}^{*} & \pi_{t}^{*} & c_{t}^{*}
\end{array}\right]^{\prime}
$$

and $u_{t}=\left[r_{t}\right]^{\prime}$. The transition matrices are defined as $\mathbf{A}=\mathbf{A} \mathbf{0}^{-1} \mathbf{A} \mathbf{1}$ and $\mathbf{B}=\mathbf{A} \mathbf{0}^{-1} \mathbf{B} \mathbf{1}$ where

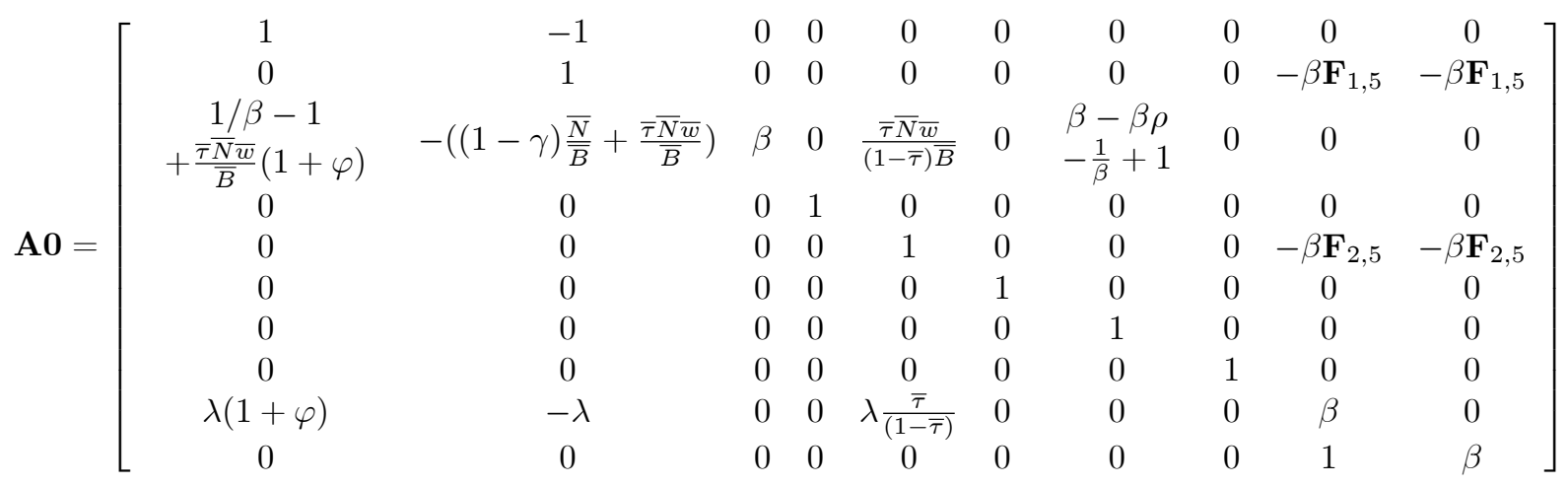

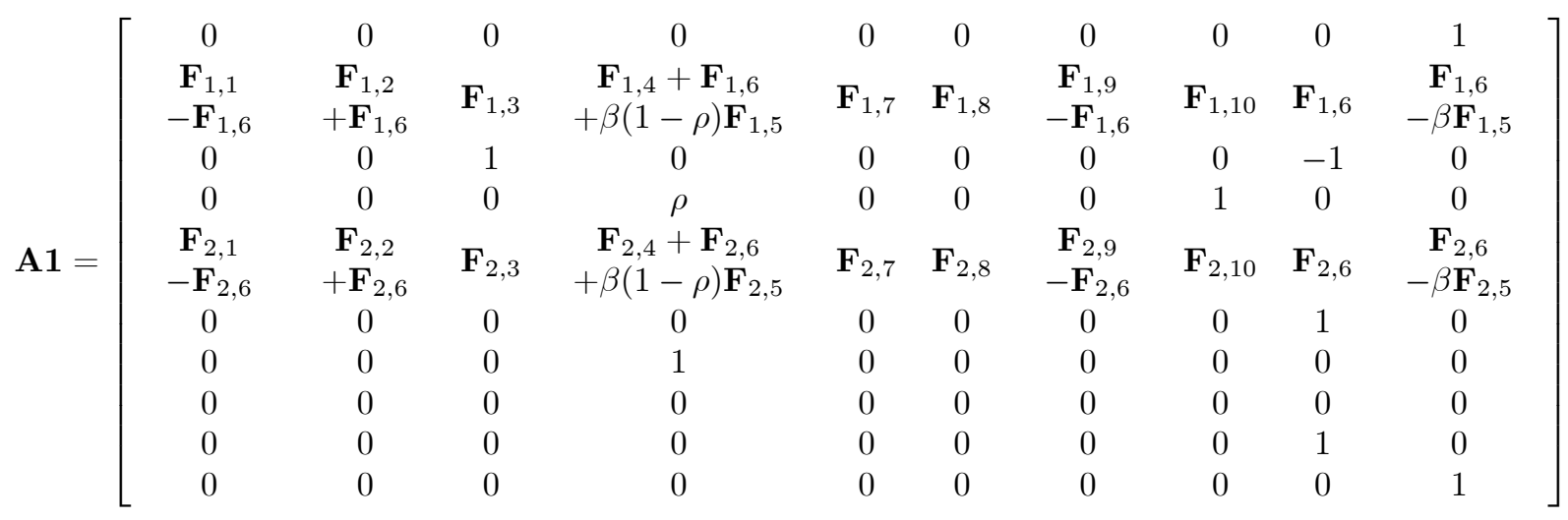


$\mathbf{B} 1=\left[\begin{array}{l}0 \\ 0 \\ \beta \\ 0 \\ 0 \\ 0 \\ 0 \\ 0 \\ 0 \\ 1\end{array}\right]$ where $F_{i, j}$ is an element of the solution from the national fiscal authorities' policy problem, $\mathbf{u}_{t}=\mathbf{F x}_{1 t}$. In other words the ECB's description of the economy includes the aggregate of the national fiscal behaviour.

The policy maker objectives can be written as,

$$
J_{0}=E_{0} \sum_{t=0}^{\infty} \beta^{t}\left[\mathbf{x}_{t}^{\prime} \mathbf{Q} \mathbf{x}_{t}+2 \mathbf{x}_{t}^{\prime} \mathbf{U} \mathbf{u}_{t}+\mathbf{u}_{t}^{\prime} \mathbf{R} \mathbf{u}_{t}\right]
$$

where $\mathbf{Q}^{e c b}=(1+\varphi) \mathbf{A}_{1}^{\prime} \mathbf{A}_{1}+\left(\frac{1}{\chi}\right) \mathbf{A}_{2}^{\prime} \mathbf{A}_{2}+\frac{\varepsilon}{\lambda} \mathbf{A}_{6}^{\prime} \mathbf{A}_{6}, U=(1+\varphi) \mathbf{A}_{1}^{\prime} \mathbf{B}_{1}+\left(\frac{1}{\chi}\right) \mathbf{A}_{2}^{\prime} \mathbf{B}_{2}+$ $\frac{\varepsilon}{\lambda} \mathbf{A}_{6}^{\prime} \mathbf{B}_{6}$, and $\mathbf{R}=(1+\varphi) \mathbf{B}_{1}^{\prime} \mathbf{B}_{1}+\left(\frac{1}{\chi}\right) \mathbf{B}_{2}^{\prime} \mathbf{B}_{2}+\frac{\varepsilon}{\lambda} \mathbf{B}_{6}^{\prime} \mathbf{B}_{6}$ where $\mathbf{A}_{j}$ is the jth row of $\mathbf{A}$. 


\section{Figures}
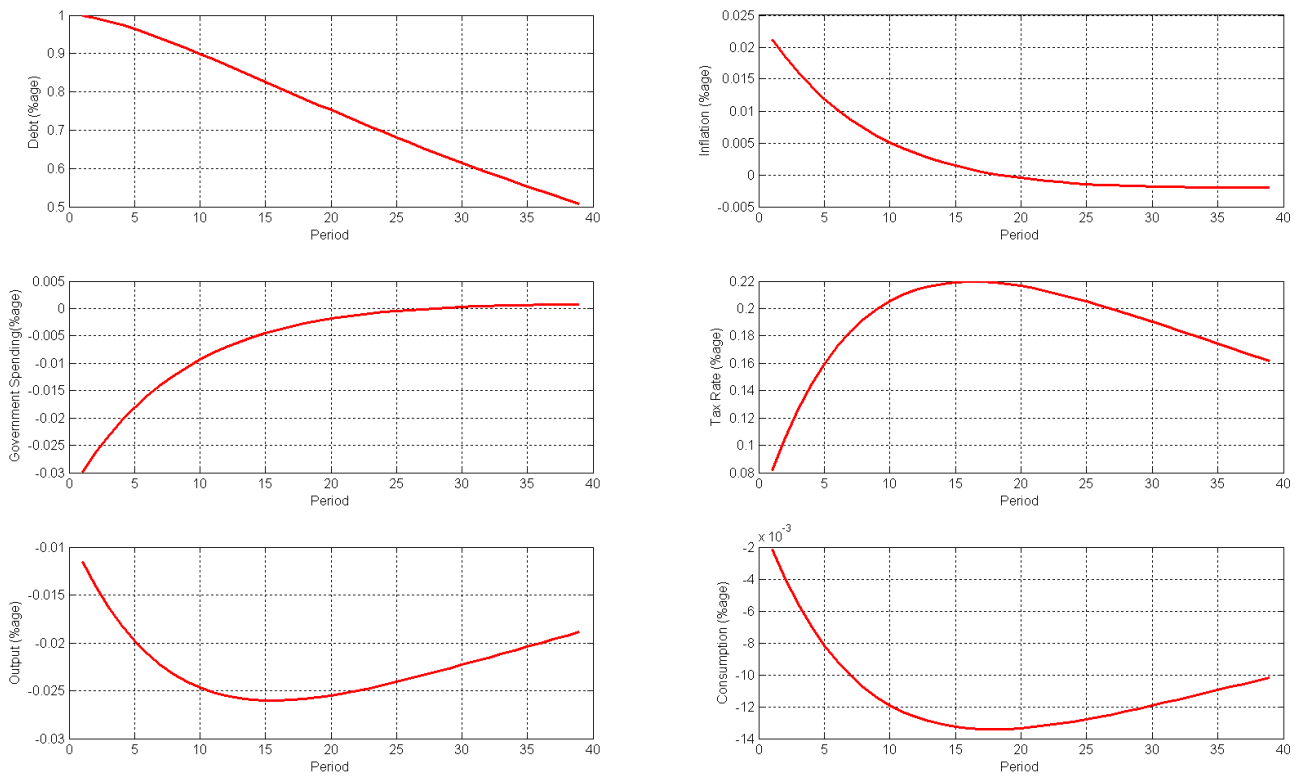

Figure 1: National Fiscal Response to a 1\% Idiosyncratic Debt Shock. 

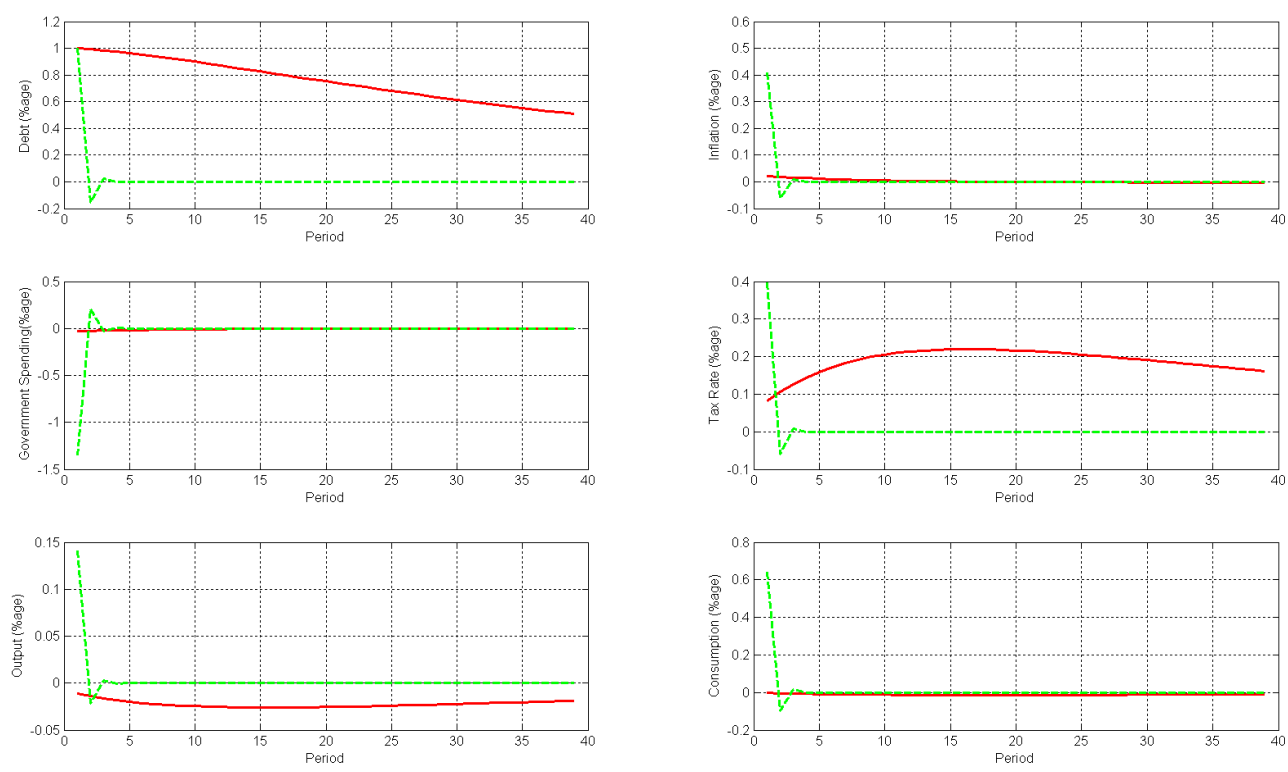

Figure 2: Nationnal Fiscal Response to an Idiosyncratic Debt Shock - EMU case (red line), Flex Exchange Rates (green dashed line). 


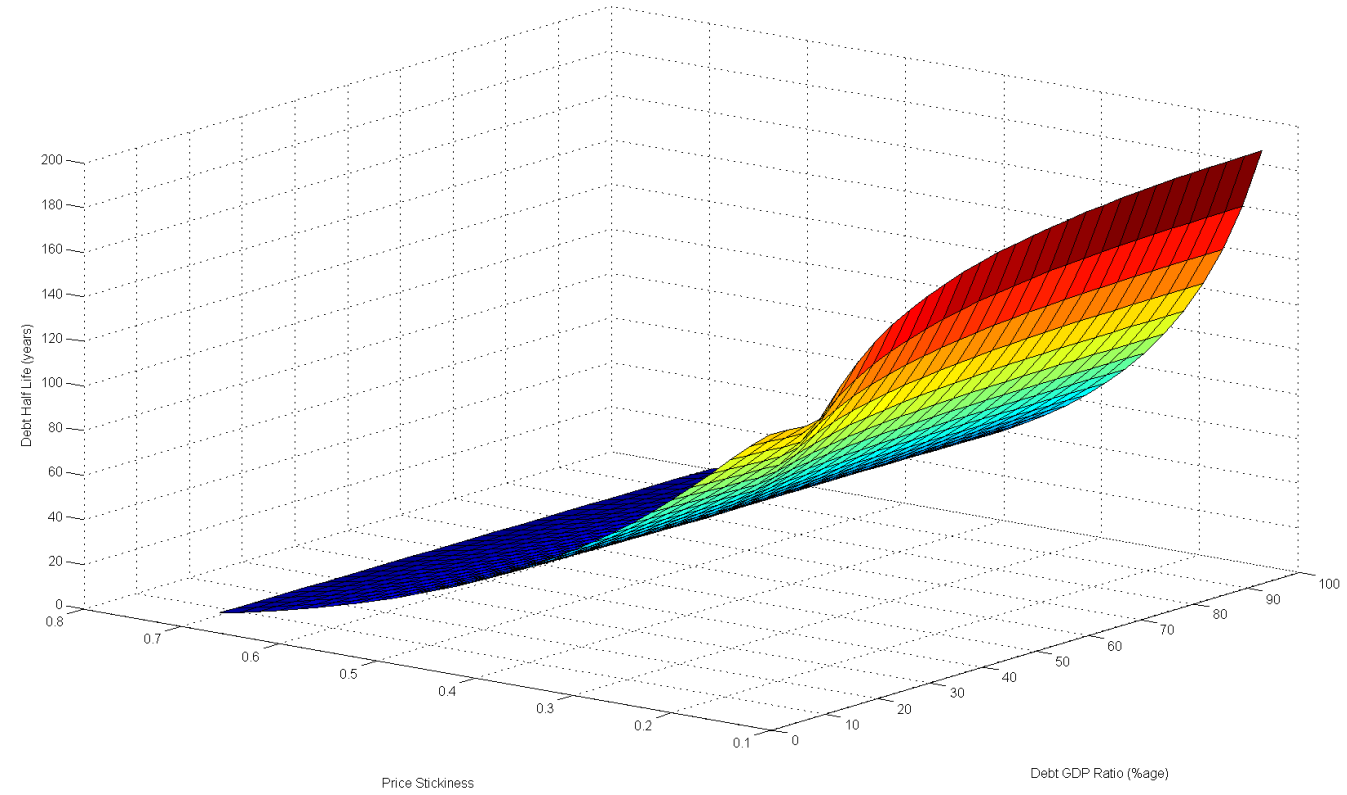

Figure 3: Half-life of National Debt as a Function of Price Stickiness and SteadyState Debt. 

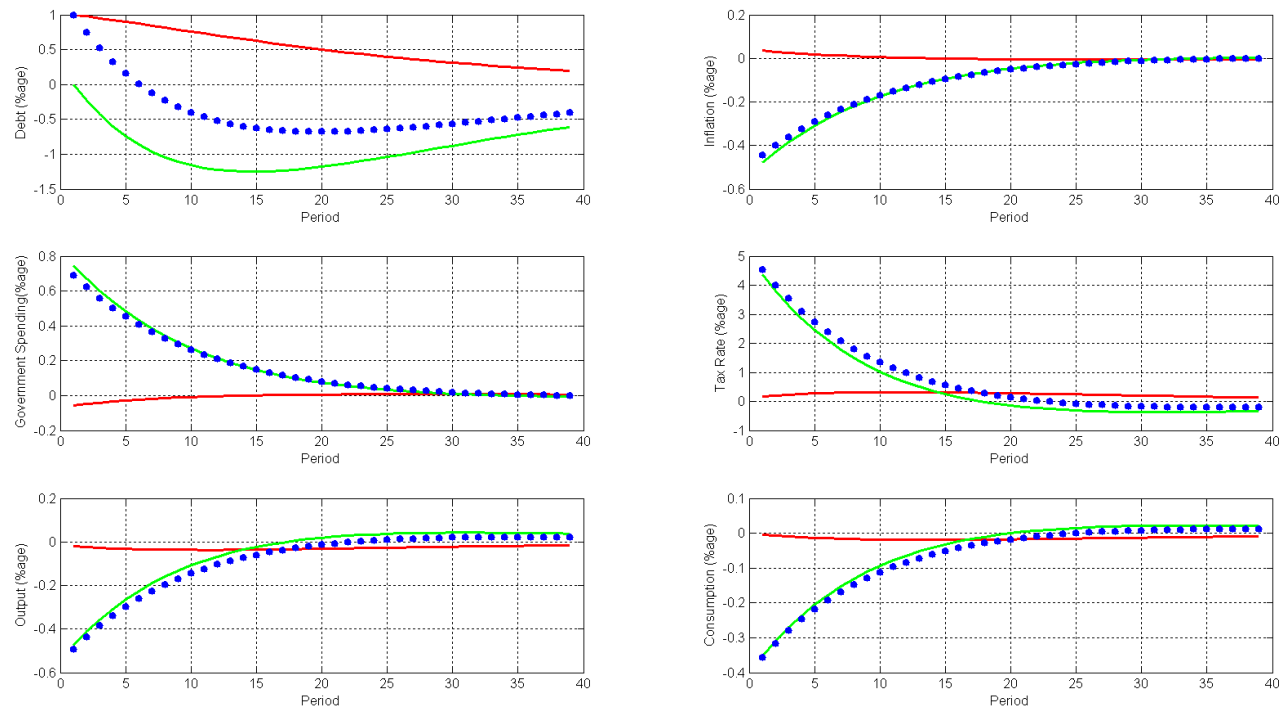

Figure 4: Competitiveness and the National Fiscal Response - Debt Shock Only (red line), Debt and Competitiveness Shock (blue dots), Competitiveness Shock Only (green dashed line). 

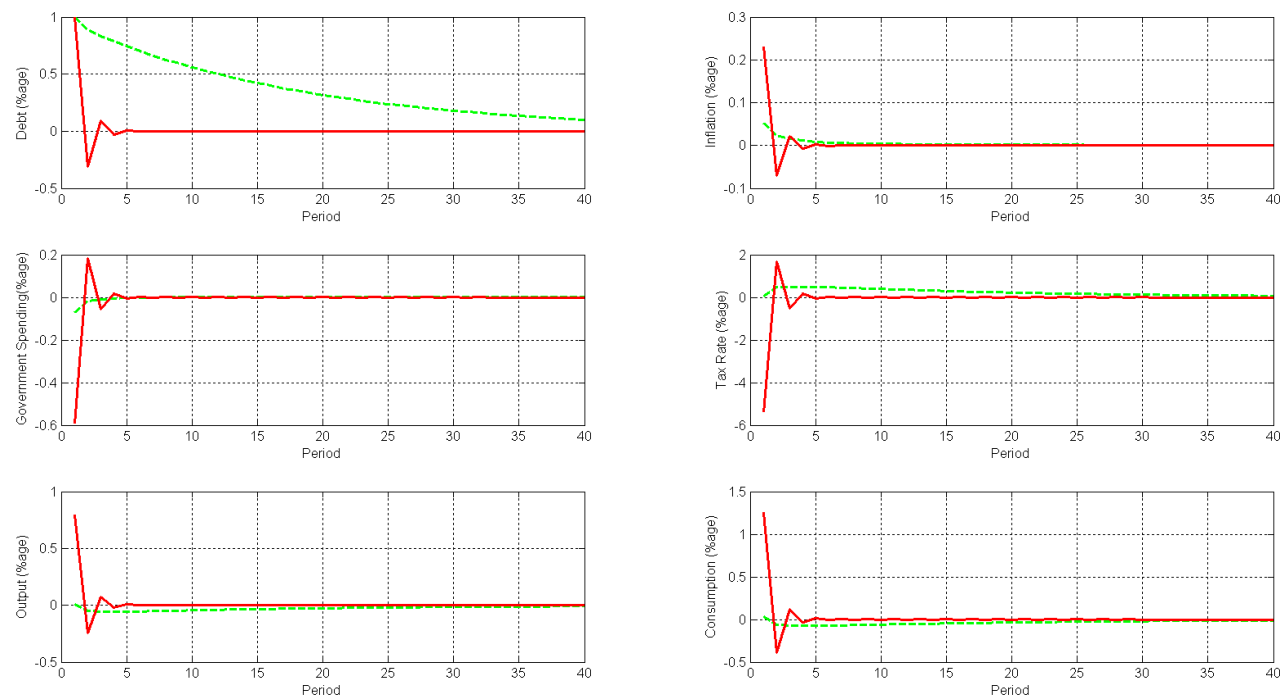

Figure 5: ECB's Response to a Union-Wide Debt Shock under Commitment (dashed line) and Discretion (solid line). 

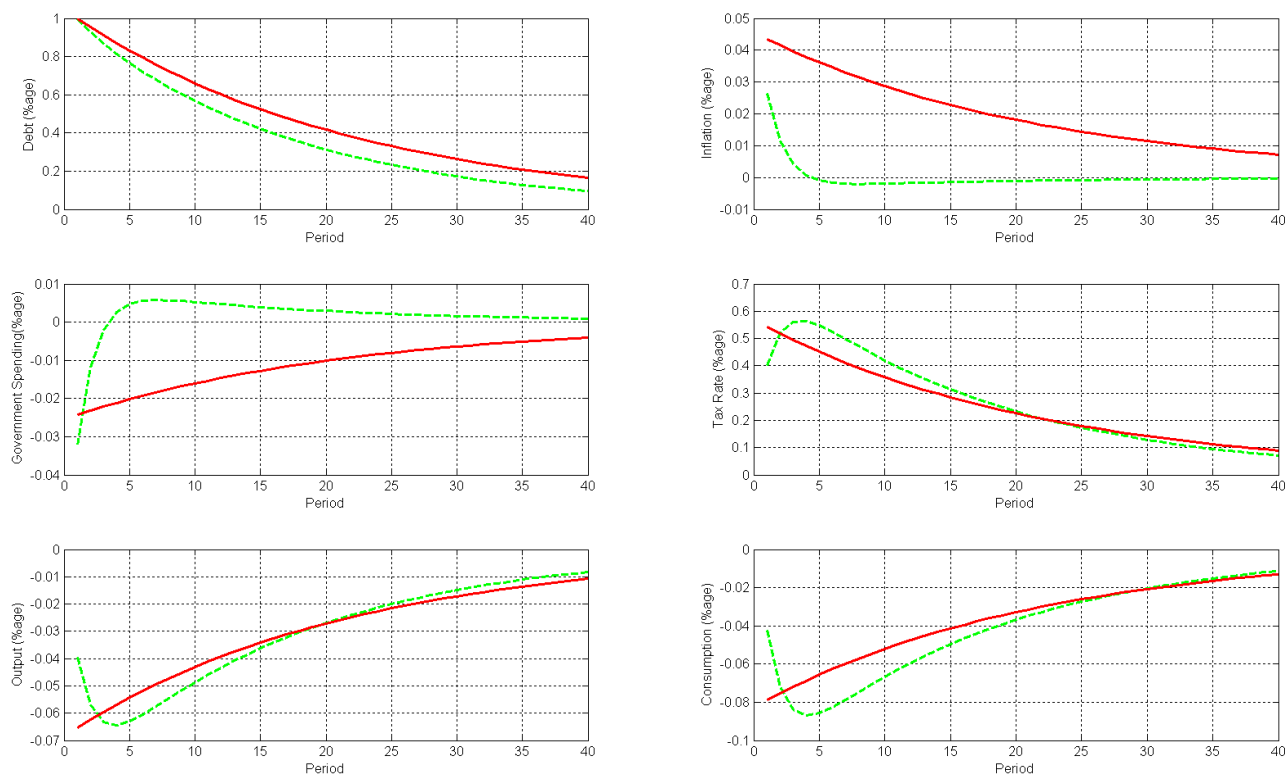

Figure 6: Conventional Assignment: ECB Ignores National Fiscal Policy under Commitment (dashed line) and Discretion (solid line). 

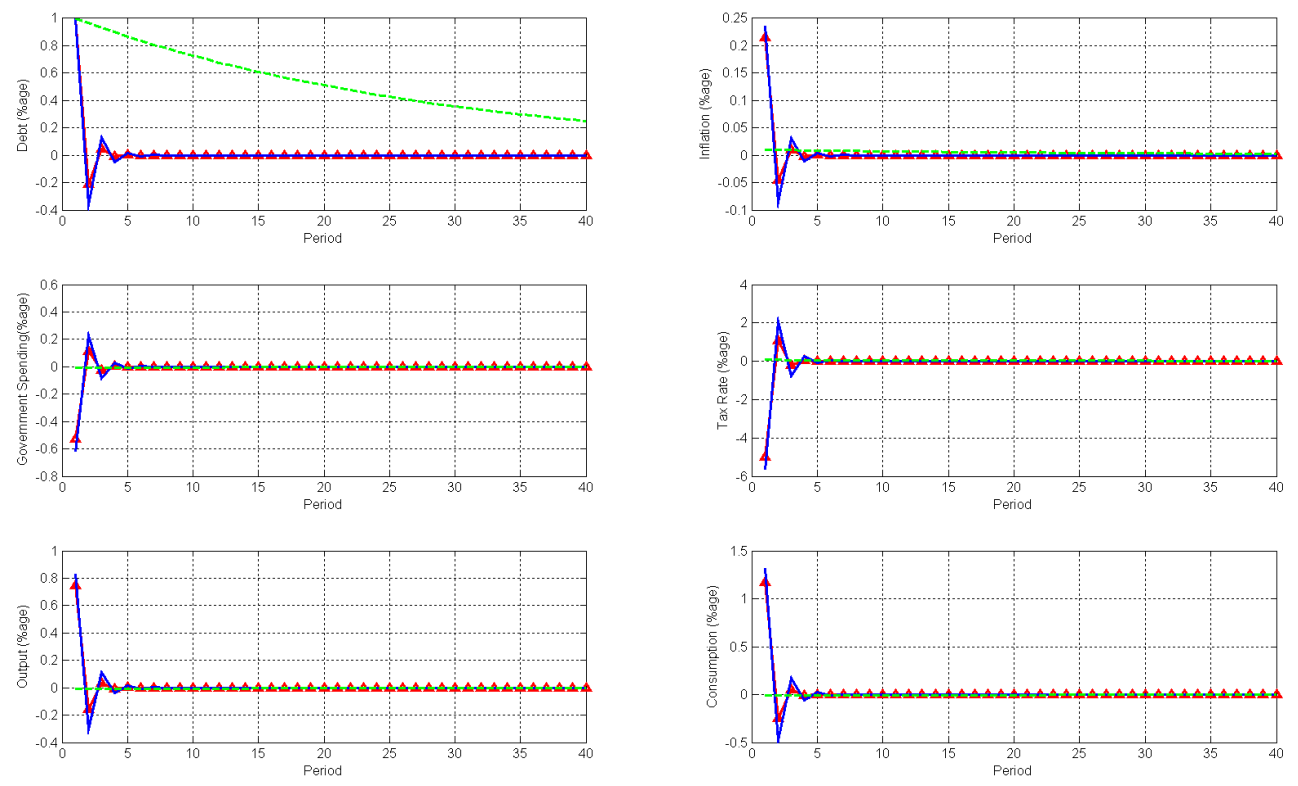

Figure 7: ECB's Time-Consistent Response to a Union-Wide Debt Shock*

*Notes to Figure - Debt-Gdp ratio is 15\% (green dashed line), 50\% (red triangles) and $80 \%$ (solid blue line). 